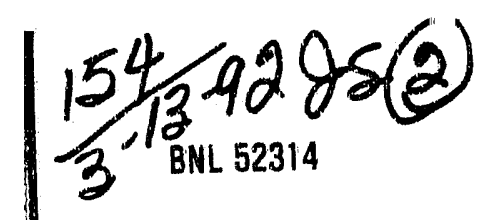

\title{
REVIEW OF THE EPA'S RADIONUCLIDE RELEASE ANALYSES FROM LLW DISPOSAL TRENCHES USED IN SUPPORT OF PROPOSED DOSE LIMITS IN 40 CFR 193
}

\author{
C. Pescatore and T.M. Sullivan
}

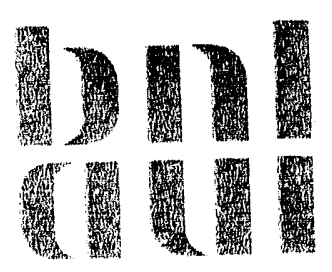

November 1991

\author{
DEPARTMENT OF NUCLEAR ENERGY \\ BROOKHAVEN NATIONAL. LABORATORY, ASSOCIATEO UNIVERSITIES. INC. \\ UPTON, NEW YORK 11973 \\ UNITED STATES DEPARTMENT OF ENERGY \\ CONTRACT NO. DE-ACO2-76CHOOD16
}




\section{REVIEW OF THE EPA'S RADIONUCLIDE RELEASE ANALYSES FROM LLW DISPOSAL TRENCHES USED IN SUPPORT OF PROPOSED DOSE LIMITS IN 40 CFR 193}

C. Pescatore and T.M. Sullivan

November 1991

NUCLEAR WASTE AND MATERIALS TECHNOLOGY DIVISION DEPARTMENT OF NUCLEAR ENERGY BROOKHAVEN NATIONAL LABORATORY, ASSOCIATED UNIVERSITIES. INC. UPTON, NEW YORK 11973

Prepared for DEPUTY ASSISTANT SECRETARY OF ENVIRONMENT, SAFETY AND HEALTH OFFICE OF ENVIRONMENTAL GUIDANCE UNITED STATES DEPARTMENT OF ENERGY 
This report was prepared as an account of work sponsored by an agency of the United States Government. Neither the United States Government nor any agency thereot. nor any of their employees, nor any of their contractors, subcontractors. or their employees, makes any warranty, express or implied, or assumes any legal liability or responsibility for the accuracy, completeness, or usefulness of any intormation, apparatus. product. or yrocess disclosed, or represents that its use would not infringe privately owned rights. Reference herein to any specific commercial product, process, or service by trade name, trademark, manu facturer, or otherwise, does not necessanly constitute or imply its endorgement, recommendation, or favoring by the United States Guvernment or any agency, contractor or subcontractor theresf. The views and opinions of authors expressed herein do not necessarily state or retlect those of the United States Government or any arency, contractor or subcontractor therent.

Printed in the United States of America Available from

National Technical Intormation Service

U.S. Department of Commerce 5285 Port Royal Road

Springfield, VA 22161

NTIS price codes:

Printed Copy: A02: Microfiche Copy: A()1 


\begin{abstract}
The April 1989 draft EPA standard for low-level waste (LLW) disposal, 40 CFR 193, would require disposal site performance to satisfy very stringent dose-limit criteria. The EPA suggests that these limits can be achieved by relying extensively on waste solidification before disposal. The EPA justifies the achievability of the proposed criteria based on performance assessment analyses in the general context of trench burial of the LLW. The core models implemented in those analyses are codified in the EPA's PRESTO family of codes. Because a key set of models for predicting potential releases are the leach-andtransport models from a disposal trench, these have been reviewed for completeness and applicability to trench disposal methods. The overall conclusion of this review is that the generic analyses performed by the EPA are not sufficiently comprehensive to support the proposed version of $40 \mathrm{CFR} 193$. More rigorous analyses may find the draft standard criteria to be unattainable.
\end{abstract}




\section{EXECUTIVE SUMMARY}

The U.S. Environmental Protection Agency (EPA) has issued in April 1989 a draft environmental standard (40 CFR 193) for the management, storage, and disposal of lowlevel radioactive waste ( $L L W)$. The standard would apply to both NRC and DOE regulated facilities.

The April 1989 draft standard identifies three major dose-limit criteria two of which are addressed in the present report. The first criterion, in Subpart B of the draft standard, would impose a $25 \mathrm{mrem} / \mathrm{yr}$ limit to an offsite member of the general public from all exposure pathways following the disposal of the waste. The second criterion, in Subpart $C$ of the standard, addresses the groundwater pathway (groundwater protection) in more detail. It would impose different dose limits for different classes of groundwaters. In particular, the EPA has drafted a zero-release limit for Class I aquifers and two options for Class II aquifers: either (a) $25 \mathrm{mrem} / \mathrm{yr}$ for low yield aquifers and $4 \mathrm{mrem} / \mathrm{yr}$ for high-yield aquifers, or (b) $4 \mathrm{mrem} / \mathrm{yr}$ for both low- and high-yield aquifers. Both the latter limits refer to an individual drinking two liters per day of affected groundwaters.

The EPA has supported the draft standard and criteria through generic performance assessment analyses of various disposal methods and options. The EPA's performance assessment analyses sought to establish (see Figure 1 of the text):

(a) over a period of 1,000 years, the maximum annual dose to people living closest to the disposal facility (critical population group),

(b) over a period of 1,000 years, the cumulative health effects to a local population in the general proximity of the disposal site, and

(c) over a period of up to 10,000 years, the cumulative health effects to the population living in the same regional basin where the disposal site is located.

Calculations related to category (a) were performed with the code PRESTO-EPA-CPG, those related to the other two categories with the code PRESTO-EPA-POP.

A core component of any performance assessment code of low-level waste sites is its set of leach-and-transport models for application within the disposal trench. Coupled with a proper module for the initial inventory of the waste, these models determine the rate of supply of radionuclides to the environmental pathways which eventually lead to man's biosphere. The leach-and-transport models implemented in the PRESTO-EPA-CPG and PRESTO-EPA-POP codes are essentially the same. The major difference between the two codes in this area is that PRESTO-EPA-CPG is more flexible than PRESTO-EPA-POP as it allows the evaluation of the concurrent leaching of several types of wasteforms. 
This report consists of a review of leach-and-transport models found in the PRESTOEPA-CPG code which was used for EPA analyses of releases to the biosphere from LI.W disposal sites.

The overall conclusion of this review is that the generic analyses performed in support of the proposed version of 40 CFR 193 are subject to question; nor can the final results be claimed to either underestimate or overestimate doses. This is because the predictions rely upon a high level of empiricism while, at the same time, are lacking the ancillary analyses that would validate data, models and release scenarios.

Several observations have been made indicating that:

1. Model assumptions were used which are often inconsistent with the available experimental data, e.g., the leach model.

2. Models were used which do not follow the progressive evolution in time of the physical characteristic of the site. For instance, it appears that the total amount of water infiltrating a trench every year is determined a priori, without supporting data, by the code user.

3. Not all pathways were explored, e.g., airborne releases of volatile compounds and elements were not evaluated.

4. The source term inventory underestimates the actual inventories of key radionuclides and it does not reflect the most typical compositions found at commercial and at DOE-controlled LL.W sites.

5. The uncertainty analysis was performed on a different set of models from those implemented in the PRESTO codes. It also used highly-peaked parameter distribution functions without justification.

6. The relative position of the drinking well with respect to the closest disposal trenches is inadequately modeled, potentially underestimating the dose to the CPG. Also, the radionuclide migration model within the aquifer is highly empirical with the code user supplying water velocity and plume aperture.

7. The analyses did not address potential intruder scenarios after the period of active institutional control of the LLW sites is over. However, it appears to request them on a site-specific basis. Thus, because an intruder could hypothetically disrupt a disposal facility and increase environmental releases, the EPA may have drafted a standard based on analyses that are less stringent than those that the EPA would expect of a license applicant.

The study does not supply an accurate means of estimating many parameters that strongly influence releases from the disposal facility. In particular, there is no justification of, or a methodology for calculating: 
a) Trench Cap Failure Rate. A linear failure rate is assumed up to a userspecified fraction of the trench cap.

b) Container Failure Rate. A user-supplied linear failure rate is assumed until $100 \%$ failure of all containers.

c) Solidified waste form leach fractions. Fractional release rate values used range from $10^{-3}$ to $5 \cdot 10^{-5}$ per year. Experimental data suggests that these values may greatly underpredict cumulative releases and release rates from solidified waste forms for many radionuclides for long periods of time.

d) Partition coefficients. The code has a data base containing values for the surface soil, trench, beneath the trench, and the aquifer. However, it is known that the values for partition coefficients may vary by several orders of magnitude depending on the local chemistry ( $\mathrm{pH}$, Eh, competing ions, soil minerals, complexing agents, etc.).

Predictions based on generic, deterministic codes such as PRESTO are acceptable only if they can be argued to be conservative with respect to all disposal scenarios which can be potentially realized. Yet many observations have been presented that this may not be the case. A further observation to that effect is possibly that the usage of this code was overextended from a tool to compare alternative disposal methods and options to a tool to support decisions for establishing LLW standards. When generic codes, such as PRESTO, are applied to situations outside their intended range, they may seem to support more stringent criteria than are warranted by a more rigorous or a more conservative analysis. For example, a 1984 analysis of the Oak Ridge site using their inventory (larger than in the EPA analyses) and more conservative assumptions: $K_{d}=0$ for all radionuclides; higher (measured) groundwater flow rates; and smaller aquifer mixing zone, lead to dose rates estimates over two order of magnitude larger than the limits proposed by EPA in 40 CFR 193.

In summary, the EPA study does not consider all of the possible release pathways that could be present; the models chosen were not always supported by relevant data, and the conservatism of some of the parameters specified are questionable. Thus, adoption of the EPA models may lead to estimates of release that are subject to major error and which may not be conservative. In this situation it may not be possible to use the recommended methodologies to demonstrate compliance with the EPA standard. 


\section{Contents}

Page

iii

ABSTRACT
EXECUTIVE SUMMARY

$\mathrm{v}$

1. INTRODUCTION

1.1 Organization of the report

2. OVERVIEW OF THE EPA MODELING APPROACH

2.1 The EPA analyses for the CPG

2.1.1 Scenario assumptions

2.1.2 Leaching model

2.1.3 Trench infiltration and groundwater transport models

2.1.4 Atmospheric transport

8

2.1.5 Results

2.2. Preliminary observations

2.2.1 Missing pathways and scenarios

2.2.1.1 Gaseous releases from the trench

2.2.1.2 Gaseous releases from surface

12

2.2.1.3 Site disruption scenarios

2.2.1.4 Failure mode and effects analysis

2.2.2 The equivalent trench and its distance from the CPG well

2.2.3 Reliance on user-supplied input parameters 
Contents (cont.)

Page

3. REVIEW OF EPA'S LEACH-AND-TR $A$ NSPORT MODELS

3.1 Waste inventory

3.1.1 Source homogenization

3.2 Water infiltration model

3.2.1 Intact trench caps

3.2.2 Failed trench caps

3.3 Leaching models

3.3.1 Fractional contact time

3.3.2 Trench $\mathrm{K}_{\mathrm{d}}$ 's

3.3.3 Leach factors

3.3.3.1 Time dependence

3.3.3.2 Dependence on specific radionuclides

3.3.3.3 Dependence on infiltration rates

3.3.3.4 Dependence on disposal method

3.3.3.5 Releases from activated metals

3.3.3.6 Reference data base

3.3.4 Early releases

3.4 Uncertainty analysis

4. CONCLUSSIONS

\section{REFERENCES}




\section{INTRODUCTION}

The U.S. Environmental Protection Agency (EPA) has issued in April 1989 a draft environmental standard (40 CFR 193) for the management, storage, and disposal of lowlevel radioactive waste (LLW). The standard would apply to both NRC and DOE regulated facilities.

The April 1989 draft standard identifies three major dose-limit criteria of which two are of concern for the present report. The first criterion, in Subpart B of the draft standard, would impose a $25 \mathrm{mrem} / \mathrm{yr}$ limit to an offsite member of the general public from all exposure pathways following the disposal of the waste. The second criterion, in Subpart C of the standard, addresses the groundwater pathway (groundwater protection) in more detail. It would impose different dose limits for different classes of groundwaters. In particular, the EPA has drafted a zero-release limit for Class I aquifers and two options for Class II aquifers: either (a) $25 \mathrm{mrem} / \mathrm{yr}$ for low yield aquifers and $4 \mathrm{mrem} / \mathrm{yr}$ for high-yield aquifers, or (b) $4 \mathrm{mrem} / \mathrm{yr}$ for both low- and high-yield aquifers. Both the latter limits refer to an individual drinking two liters per day of affected groundwaters. ${ }^{1}$

The EPA has supported its draft standard and criteria through generic performance assessment analyses of various disposal methods and options. With reference to Figure 1, the EPA's performance assessment analyses sought to establish:

(a) over a period of 1,000 years, the maximum annual dose to people living closest to the disposal facility (critical population group),

(b) over a period of 1,000 years, the cumulative health effects to a local population in the general proximity of the disposal site, and

(c) over a period of up to 10,000 years, the cumulative health effects to the population living in the same regional basin where the disposal site is located.

Calculations related to category (a) were performed with the code PRESTO-EPA-CPG, those related to the other two categories with the code PRESTO-EPA-POP (Figure 1).

A core component of any performance assessment code of low-level waste sites is its set of leach-and-transport models within the disposal trench. Coupled with a proper module for the initial inventory of the waste, these models determine the rate of supply of radionuclides to the environmental pathways which eventually lead to man's biosphere. The leach-and-transport models implemented in the PRESTO-EPA-CPG and PRESTO-EPAPOP codes are essentially the same. The major difference between the two codes in this

1 The DOE has not formally classified the groundwaters under its sites. However, it appears that most DOE sites may potentially overlie high-yicld Class II aquifers. 


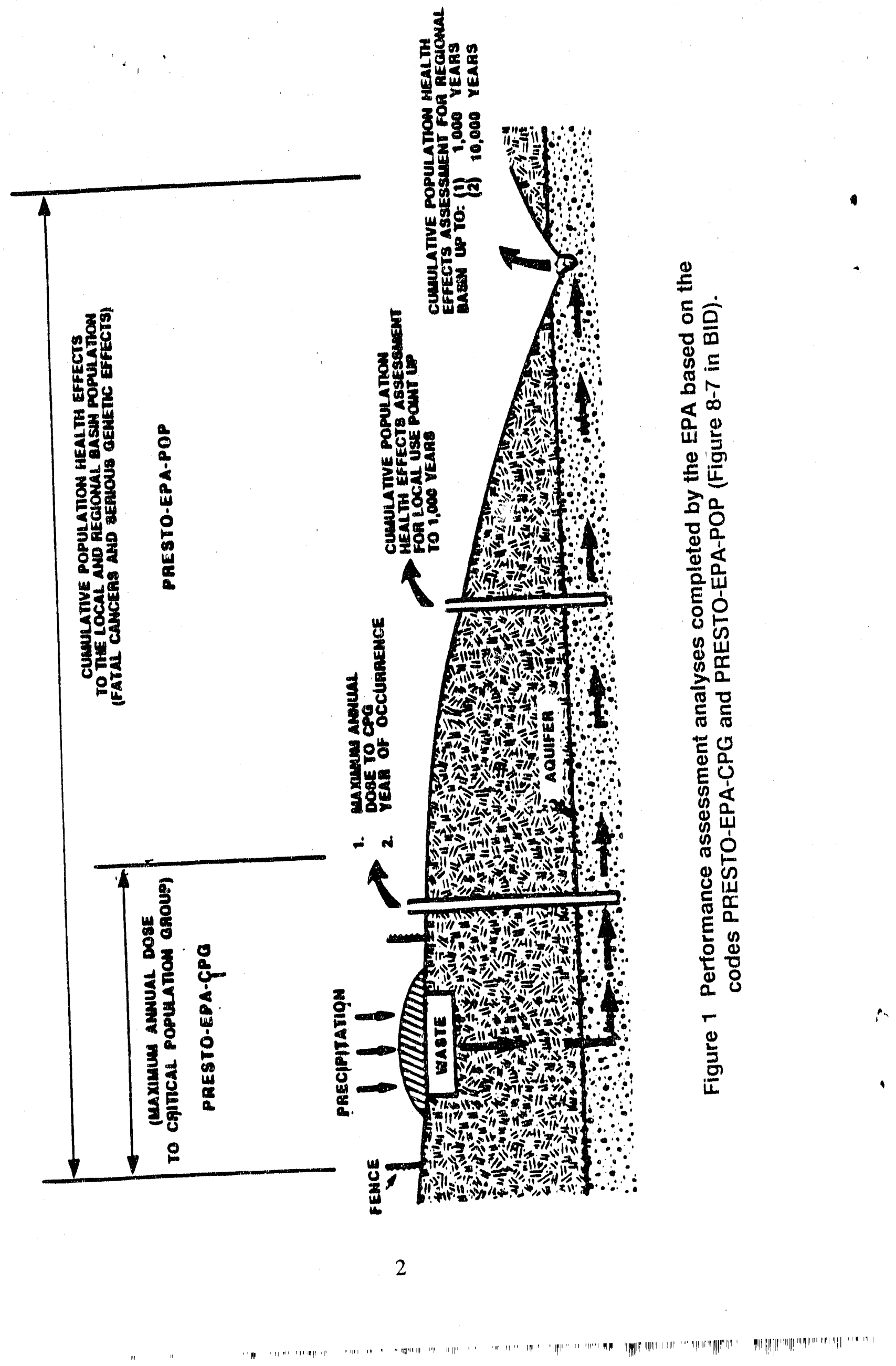


area is that PRESTO-EPA-CPG is more flexible than PRESTO-EPA-POP as it allows the evaluation of the concurrent leaching of several types of wasteforms.

Because we are interested, for the most part, in a review of leach-and-transport models we shall concentrate chiefly on the EPA analyses based on the PRESTO-EPA-CPG code.

\subsection{Organization of the report}

Chapter 2 presents an overview of the EPA's radionuclide release analyses from LLW disposal facilities. Based on this overview, we offer some general comments on the modeling approach.

Chapter 3 presents a detailed discussion of the models in PRESTO-EPA-CPG that pertain to leaching and transport of radionuclides from the waste. Emphasis was placed on reviewing the leaching models; however, where appropriate, we also reviewed EPA's assumptions on water infiltration, inventory, and the uncertainty analyses presented in the EPA's Background Information Document [BID, 1988].

Chapter 4 presents our conclusions. 


\section{OVERVIEW OF THE EPA MODELING APPROACH}

\subsection{The EPA analyses for the CPG}

PRESTO-EPA-CPG was the code used by the EPA to estimate the maximum annual dose to the so-called Critical Population Group (CPG) for a time period of 1,000 years following disposal operations. ${ }^{2}$ The code is reportedly able to analyze land disposal of LLW by shallow or deep methods. In particular, the code addresses both groundwater and atmospheric transport pathways to the CPG.

\subsubsection{Scenario assumptions}

The backgrciund information document [BID, 1988] to 40 CFR 193 indicates that three disposal environments were considered in the EPA's analyses. With reference to Figure 2, these environments represent:

(a) a permeable medium in a humid climate,

(b) an impermeable medium in a humid climate, and

(c) a permeable medium in an arid climate.

For cases (a) and (c) the dose rates to the CPG were calculated by assuming that an individual uses water drawn from a well located downgradient from the disposal facility. ${ }^{3}$ For case (b) the dose rate calculations assumed that the CPG individual would derive his or her drinking water from a stream contaminated with water overflowing from the disposal facility.

"All major non-intrusion human exposure pathways are considered." [CPG, p. 1-3] Indeed, although the NRC regulations require addressing intruder protection (10 CFR 61.42), "EPA feels that this exposure pathway is probabilistic in nature and that safeguards against inadvertent intrusion should be carried out on a site-specific basis. For these reasons, EPA has not included intrusion scenarios in its health impact assessments. " [BID, p. 8-12] The EPA, however, implemented a different philosophy when addressing the disposal of Below Regulatory Concern (BRC) waste. In those analyses biointrusion and ingestion of food grown onsite were considered [BID, § 8.5.2].

2. "Lifetime risk to a member of the CPG is estimated using the maximum annual dose rate, assuming it remains constant over the lifetime of the individual (average of 71 years)" [BID, p. 8-30].

3 The CPG sample problem [CPG, p. 6-1] locates the well 259 meters away from the cunter of the trench sistablatiog the oricrinal disposal unit. The equivalent trench is modeled as leaking from its center. 


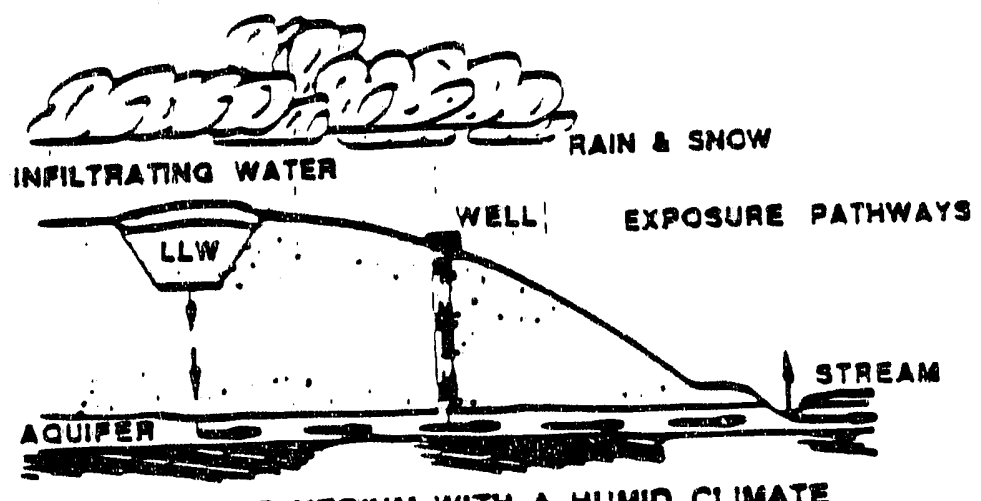

a) PEAMEABle mediuM WITH a huMID CLIMATE

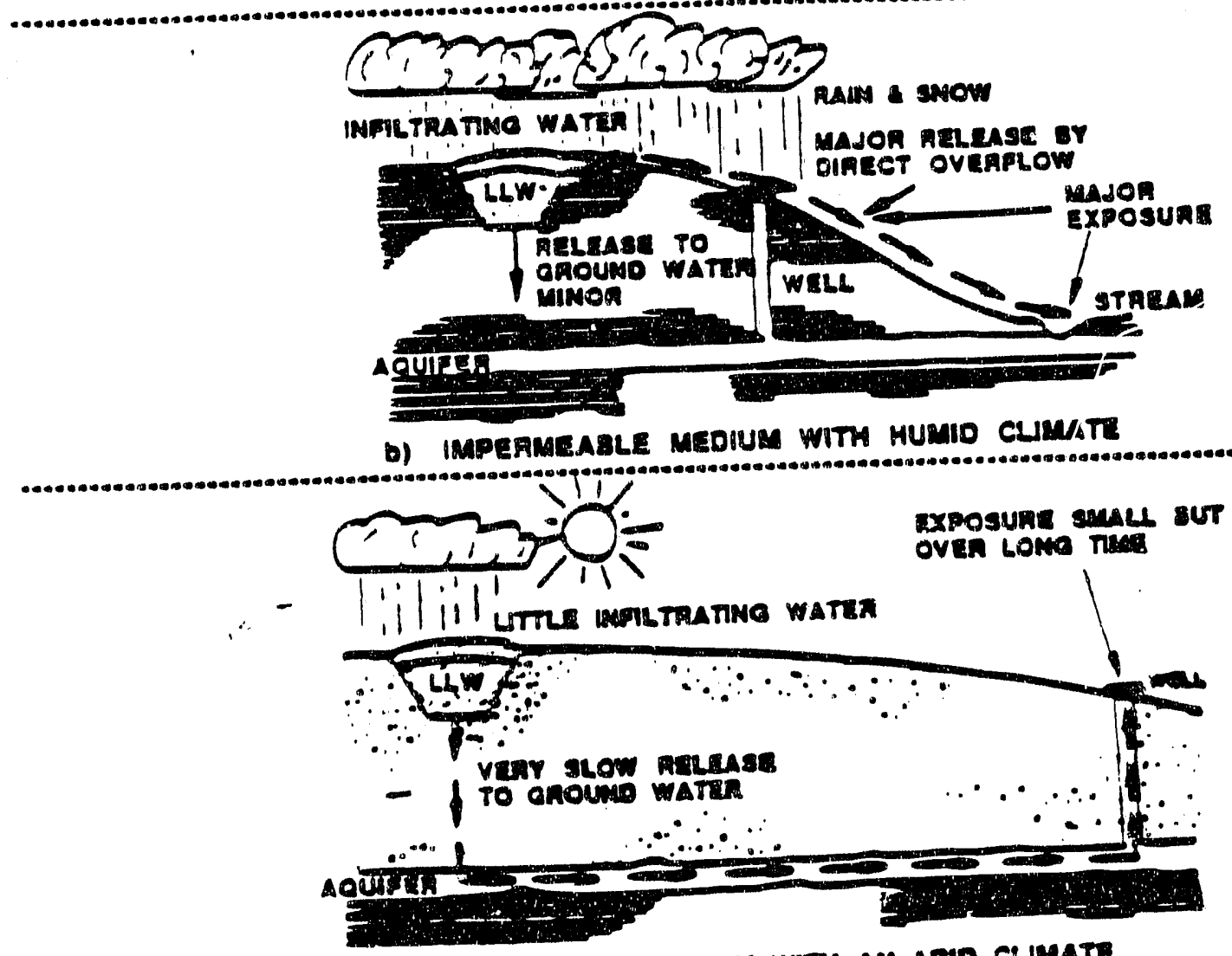

c) Penmeagla musuum with an aho cimats

Figure 2 Environmental pathways at a shallow LLW disposal facility in the three reference, general hydrogeologic and climatic settings (Figure 8-6 in BID). 
Another important assumption in the EPA analysis is that no nuclide migration is initiated during active maintenance of the disposal site, although radioactive decay is accounted for. This effectively reduces the inventory of short half-lived radionuclides available for release from the disposal trenches.

\subsubsection{Leaching model}

The source term for the CPG analysis groups all waste streams into one of five possible wasteforms:

(1) absorbing materials,

(2) trash,

(3) solidified waste,

(4) activated metals, and

(5) incinerated -solidified waste.

From a leaching point of view these can be subdivided into two categories plus an intermediate one: Category I comprises all so-called "absorbing materials;" Category II comprises activated metals, all solidified waste, and incinerated-solidified waste. Trash is user-apportioned between the two categories.

For Category I waste, leaching is regarded as a sorption equilibrium process whereby each radionuclide has its own environment-dependent distribution coefficient, $\mathrm{K}_{\mathrm{d}}$. Within Category II, each wasteform leaches according to its own characteristic, nuclide independent, user-supplied leach factor (LF). Concurrent leaching of both waste categories is also accounted for. The concentration of radionuclides in the trench water is obtained by letting the Category II waste leach over a single year, by adding the leached-out inventory to the inventory of radionuclides present in the absorbing materials, and by apportioning the combined inventory between the liquid and the solid phase via the effective $K_{d}$ for the absorbing materials. Reportedly [CPG, p. 3-4], a solubility check is also performed to make sure that the concentrations in the water never exceed the solubility limits. ${ }^{+}$

\subsubsection{Trench infiltration and groundwater transport models}

For groundwater transport calculations, rainwater is assumed to infiltrate from the trench cap and to exfiltrate vertically through the bottom of the trench reaching eventually the underlying aquifer. The one-dimensional plume of contaminated water then migrates horizontally downgradient to the CPG drinking well (Figure 2). When the infiltration rate is such as to cause the trench to overflow, transport in the surface run-off is also accounted

4 It appears, however, that a solubility check was not performed in the supporting analyses for 40 CFR 193 [BID, p. C-6]. It would be extremely difficult to justify generic solubility values applicable to any disposal site. 
for. Retardation to contaminant migration, both with the surface run-off and underground, is modeled through the use of effective $K_{d}$ values.

More in particular, the rate of "Infiltration is computed using a method by C.Y. Hung (Hu83b). This method simulates the infiltration of rainwater through a trench cover by modeling three separate flow systems: subsurface, overland, and atmospheric. Normal infiltration rates, calculated by the model, occur on the intact portions of the trench cap. On the failed portions, the infiltration also includes all the surface runoff that is diverted into the trench from the area of the trench cap up-slope from the failure area. Failure of the trench cap is through erosion or other processes. Erosion is determined by the model based on input parameters. However, in most cases, an actual trench cap will fail from such processes as subsidence, gully formation, or mechanical disturbance. To model these cases, the failure of the trench cap is based on assumed failure percentages occurring in user-specified years." [BID, p. 8-7]

\subsubsection{Atmospheric transport}

"For atmospheric transport calculations, the entire population is assumed to reside within the same 22.5 degree sector. User specified parameters give the fraction of the year that the wind blows into that sector." [CPG, p. 1-6]. Atmospheric transport models only the mechanical resuspension, in particulate form, of radionuclides spilled over the surface soil during site operations or due to the overflow of trench water after closure of the disposal unit. "No gaseous emissions, such as methane, carbon dioxide, or water vapor, are included in the source term." [BID, p. 8-10]

\subsubsection{Results}

The results of the CPG analyses are reported as follows [BID, p. 8-31]:

"At the humid permeable site, the maximum dose occurs through the groundwater pathway. The important nuclides are those with high mobility (low $K_{\alpha}$ ) values such as $\mathrm{H}-3, \mathrm{C}-14$, and I129. They reach the critical population within 1,000 years when combined with re!atively high groundwater velocities.

At the humid impermeable site, the maximum dose occurs within about 100 years of failure of the trench cap (assumed to occur in year 100) via trench overflow directly to the surfacewater pathway. The important nuclides are those that are relatively mobile and have longer half-lives. An example is 1-129, which reaches the critical population group soon after the trench cap fails. It leaves the trench via overflow and is transported directly to the local stream by surface water, thus bypassing the greater retardation it would have if it had moved through the ground. Nuclides with shorter half-lives, such as H-3, cause few high doses due to their decay during the period the trench cover remains intact.

At the arid permeable site, the maximum dose can occur in the first year after closure because of the atmospheric transport of less mobile radionuclides, such as $C 0-60, C 5-137$, and 
Ba-137m, spilled onto the surface soil during site operations. This dose is very small (much less than one mrem). ... A greater dose may occur through the groundwater pathway, either late in the modeling period or even after 1,000 years. The later doses can be significantly larger, although still very small (much less than one mrem), are dominated by mobile radionuclides with relatively long half-lives, such as C-14 and I-129." [BID, p. 8-31]

From the point of view of a sensitivity analysis, the EPA comments on its own results as follows:

"At the humid permeable site, the maximum dose rate to the CPG is most sensitive to parameters that have an effect on: the amount of water infiltrating into the trench, such as the percentage trench cap failure and the trench cover permeability and porosity; the rate at which radionuclide contaminated leachate leaves the waste matrix and then the trench, such as waste container related parameters, duration of institutional control, and nuclide specific release fractions and distribution coefficients; and radionuclide transit time in groundwater, such as the distance from the trench to the aquifer and the well.

At the humid impermeable site, the maximum dose rate to the CPG is most sensitive to parameters that affect the release to the surface water system and transit time of mobile and relatively long-lived nuclides, such as the percentage trench cap failure, waste container related parameters, and the nuclide specific release fractions.

At the arid permeable site, the maximum dose to the $C P G$ is most sensitive to parameters that modify groundwater transport characteristics, such as increasing the amount of trench failure, decreasing the trench-to-aquifer distance, or increasing the aquifer flow rate. In addition the spillage fraction and atmospheric pathway parameters are very sensitive for the scenarios where short-term, atmospheric pathway doses dominate.

In summary, the PRESTO-EPA-CPG code exhibits greater relative sensitivity to changes in input parameter values than does the PRESTO-EPA-POP code. This is because the impact that is assessed, maximum dose to the CPG, is sensitive to small changes due to the model's assessing' peak doses over short time periods to individuals close to the disposal sites. Because the modiel is evaluating maximum doses relatively soon after disposal, sensilive parameters are those that affect leaching and transport of highly mobile, short-lived radionuclides, such as $H-3$. In addition, the maximum will be very sensitive to the source term and release of mobile radionuclides." [BID, p. 11-16]

\subsection{Preliminary observations}

Based on the materials contained in the foregoing paragraph, a few preliminary observations can be made. In particular, it appears that in the EPA analysis:

(1) not all pathways and scenarios have been explored; 
(2) the geometric relations between the disposal site and the well location appear to be inadequately modeled;

(3) the code results are very sensitive to user-supplied, highly-uncertain, empirical input parameters;

(4) as performed, the analysis may not be sufficiently comprehensive for use in a standard licensing review; and

(5) the EPA appears to have extended the application of the PRESTO codes beyond their original intended usage.

\subsubsection{Missing pathways and scenarios}

\subsubsection{Gaseous releases from the trench}

The EPA analyses neglect gaseous emissions of key radionuclides, such as ${ }^{3} \mathrm{H}$ and ${ }^{14} \mathrm{C}$, from the trenches and give no justification for this assumption.

With regard to ${ }^{14} \mathrm{C}$, a recent EPA report indicates that two thirds of the ${ }^{14} \mathrm{C}$ inventory present in a commercial LLW disposal trench are likely to be released through a gaseous pathway and only one fourth through the groundwater (Figure 3) [EPA, 1986].

"The transport of C-14 from the low-level radioactive waste site is believed to be largely as a gaseous release to the atmosphere". "The primary source of the ${ }^{14} \mathrm{C}$ that eventually leaks off as carbon dioxide and methane gas to the soil and atmosphere is from the organic radiocarbons of the institutional and industrial waste categories." "The chemical form of the institutional and industrial carbon-14 waste is believed to be essentially 100\% organic radiocarbon compounds." "Institutional and industrial waste comprises approximately 64 percent of the projected total inventory of C-14 to the year 2000" [EPA, 1986]. It is to be noted that a substantial fraction of the ${ }^{14} \mathrm{C}$ activity is disposed of in Class $\mathrm{A}$ waste, i.e., the least effectively stabilized waste [NRC, 1990]. This activity may become available for release at relatively early times. Later on, the ${ }^{14} \mathrm{C}$ activity disposed of as Class $\mathrm{B}$ and Class $\mathrm{C}$ waste may also become available for release because this radionuclide does not decay significantly over a period of 1,000 to 10,000 years.

Another important radionuclide for gaseous release is the highly-mobile ${ }^{3} \mathrm{H}$. Although it has a relatively short half-life ( 12 years), it represents a large fraction of the initial activity in a disposal trench. ${ }^{3} \mathrm{H}$ transport in the vapor phase from subsurface burial has been reported in the literature. Wheeler and Warren [Wheeler, 1975] report that at Los Alamos National Laboratory (LANL) the migration of tritium from subsurface disposal shafts in the unsaturated zone "... occurs through movement of tritiated water vapor through rock material ... the principal pathway for migration out of the disposal shafts is the joints that intersect them". At LANL, LLW has also been disposed of in burial "pits" 8 meters or less in depth, a couple of hundred meters long, and about 30 meters wide. A LANL report [Abeele, 1981] found that "The gradual mixture of tritiated water with natural soil moisture and subsequent 


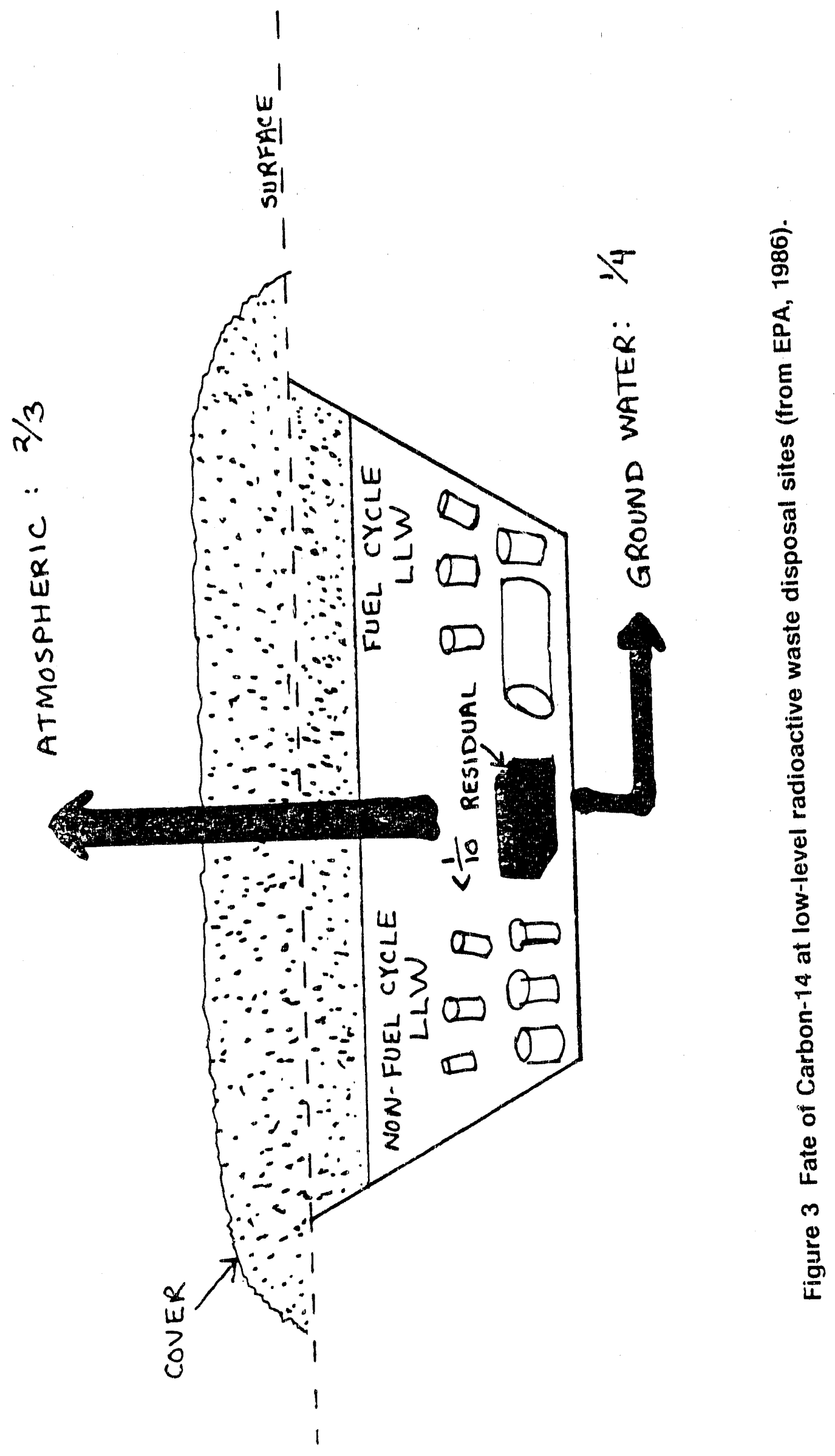


evaporation of that water from the soil to the atmosphere results in a gaseous release from the burial ground." "High release rates around the end of summer and beginning of fall are expected if the observations follow a seasonal patterm. Air concentrations in 1980 that are partly influenced by soil releases (absolute humidity, wind speed, and atmospheric convection will play an important role) also show a maximum during the warmer months and an overall minimum during the month of December."

For disposal sites in humid areas, the airborne release of tritium correlates directly with the distance of the water table from the ground level. A recent study [Amano, 1987] performed at Oak Ridge determined that "... Tritium concentrations in air show both spatial and seasonal variations. Concentrations in air moisture at different heights aboveground are more uniform during summer than during winter. This difference is attributed to the presence of tritiated water vapor transpired by tree foliage and the drying of the surface soil during summer. During winter the water table is nearer to the soil surface, so tritium concentrations in air moisture collected near the ground become elevated." A further significant finding is the observation of Francis [Francis, 1984] who reported tritiated methane as the most abundant detected seepage gas to the atmosphere from the West Valley burial trenches, indicating an important contribution from microbial activity.

${ }^{129} \mathrm{I}$, another important radionuclide for assessing the dose to man from L.LW disposal, may also have gaseous release pathways because it is a semi-volatile element. Furthermore, the possibility cannot be excluded that other radionuclides, chiefly as a result of chemical microbial activity while in the trench environment, may form volatile compounds.

\subsubsection{Gaseous releases from surface waters}

Gaseous releases of radionuclides such as ${ }^{3} \mathrm{H}$ and ${ }^{14} \mathrm{C}$ are also important to assess potential overspillage scenarios whereby these radionuclides are transported with the surface waters. The latter are subject to evaporation and to isotopic exchanges between the radionuclides in the air and in the water.

The addition of gaseous release pathways to the EPA analysis may change significantly their estimates of the total committed dose to the CPG, especially for the impermeable site with a humid climate.

\subsubsection{Site disruption scenarios}

The EPA analysis does not address site disruption scenarios through which a potential intruder may cause higher doses to members of the general public. It is not clear to what extent a potential license applicant may neglect those scenarios. This information should be supplied by the EPA. 


\subsubsection{Failure mode and effects analysis}

Generally, it appears that, in the EPA analysis, a formalized procedure for performing a failure modes and effects analysis (FMEA) of disposal scenarios was not instituted.

The FNEA is the main operational tool of qualitative reliability analysis. It provides an identification and screening of the various failure modes that contribute to system unreliability. An FMEA is an integral part of early design evaluation and should be periodically updated to reflect changes in design or application. These FMEAs often uncover hidden faults and weaknesses which can be corrected early in the design process or suggest relevant areas for further study and experimentation.

If performed by the EPA, this analysis might have addressed, at least qualitatively, the gaseous release pathway and the potential impact of microbial activity within the disposal trenches. It would also have provided information on the extent to which site disruption scenarios can be considered negligible.

\subsubsection{The equivalent trench and its distance from the CPG well}

PRESTO-EPA-CPG models releases as occurring from a single equivalent trench with user-supplied surface area and depth. The length of the trench is not specified. The trench is supposed to leak from its center, and the distance to the CPG well is measured from the center of the trench 5 .

On the other hand, disposal sites implementing trench burial methods are normally comprised of several tens of trenches. Different trenches often isolate wastes of different classes. Thus there may be trenches with Class A waste, others with Class B waste, and others yet with Class $C$ wastes. Since the CPG drinking well will be much closer to a few disposal trenches rather than to the center of the disposal site, it becomes imperative that the relative position of the well with respect to the closest trenches be properly accounted for along with the waste composition of these trenches. One may obtain very different results if the contamination to the CPG well comes from burial trenches $100 \mathrm{~m}$ away or for example, from waste leaking to the groundwater 260 meters away. Furthermore, if the well distance from the trenches is comparable to or smaller than the typical length of a trench, a 1-D model for contaminant migration to the well may not be acceptable.

Because of the above observation, and because of the reported sensitivity of the EPA results to the location of the drinking well (Section 2.1.5), the CPG analysis performed by the EPA cannot be said to be either conservative or realistic. In fact, in an actual disposal

5 For instance, the CPG sample problem implements a trench area of $100,000 \mathrm{~m}^{2}$ and a CPG well located $259 \mathrm{~m}$ from the trench center. If the equivalent trench is thought as having the form of a square, this corresponds to a square of $330 \mathrm{~m}$ side, roughly, while the well is $(259-330 / ?)=194$ meters away from the edge of the disposal site. 
situation, it may underestimate significantly the maximum dose rate to the affected individuals.

\subsubsection{Reliance on user-supplied input parameters}

The EPA source-term for release calculations is comprised of three main elements: (1) the infiltration rate of rainwater in the trench, (2) a leaching model, and (3) a groundwater transport model to the closest well.

The rainwater infiltration model depends most sensitively on the failed fraction of trench caps. The latter is provided as user-supplied fallure percentages occurring in userspecified years. For instance, in the CPG sample problem, cover failure begins in the year 100 after disposal and increases linearly up to a maximum and final value of $20 \%$ at year 300 .

The leaching model does not follow the wasteform degradation over time. Rather it is an empirical model whereby the container degradation rate is user-supplied. After container breach, for solidified waste, the leach rate depends most sensitively on usersupplied $K_{d}$ values and on assumed, user-specified leach factors which are nuclideindependent and constant over time.

The groundwater uptake in the CPG well depends on a 1-D contaminant dispersion model from a point source (the center of the trench). The model relies, for instance, on user-specified velocity of the groundwater in the aquifer and on a user-supplied dispersion angle of the pollutant plume in the aquifer.

It is clear that significant reliance on empirical values as well as on empirical models raises questions regarding the applicability, general validity, and conservatism of those parameters and models. These issues deserve further attention and will be addressed in the Chapter 3 of this document.

\subsubsection{Onsite intruder protection}

Although the PRESTO-EPA codes are reportedly able to calculate exposures "for onsite intruders who may grow crops with roots into the waste or build houses over the waste" [BID, p. 8-2], the EPA, in its health impact assessments of LLW disposal sites, did not include intrusion scenarios following the period of active control of the sites "because these involve probabilistic aspects to be evaluated on a site specific basis" [BID, \$ 8.3.3]. Onsite farming, however, was analyzed as an intrusion scenario for $\mathrm{BRC}$ waste sites [BID, § 8.5.2]. Postclosure exposures to onsite residents of BRC sites were modeled as occurring "through two pathways - ingestion of food grown onsite and biointrusion."

Other agencies have stated implicit or explicit dose limits for onsite intruders' protection. In particular: 
(a) in the drafting of the NRC rule, $10 \mathrm{CFR} 61$, the inadvertent intruder scenarios analyses were so important that "The Commission established concentration limits for radionuclides based on a number of consideration, including protection of a potential intruder..." [FR, 1982; p. 57455]. In fact, the basis of the NRC waste classification limits is a 500 mrem whole body dose limit to a potential intruder. This limit was recommended to the NRC by the EPA "... coupled with ALARA as the basis for determining the concentration. limits in Table 1 Part 61." [FR, 1982; p. 57449].

(b) onsite intruder protection is addressed as an important performance objective by the DOE order 5820.2A of $9 / 26 / 88$. The latter ensures that the "committed effective dose equivalents received by individuals who inadvertently may intrude into the facility after the loss of active institutional control (100 years) will not exceed $100 \mathrm{mrem} / \mathrm{yr}$ for continuous exposure or $500 \mathrm{mrem}$ for a single acute exposure." [DOE, 1988; p. III-2] These dose limits contrast with the DOE's $25-\mathrm{mrem} / \mathrm{yr}$ dose-limit to the general public from normal exposure.

Since the EPA draft standard does not apply to the protection of onsite intruders, while at the sarne time, intruder scenarios analyses might be requested "on a site specific basis" by the EPA [BID; p. 8-12], it is not clear to what extent the intruder protection dose limits of the NRC and the DOE may be acceptable to the EPA.

\subsubsection{Expected level of rigor}

The draft 40 CFR 193 of April 1989 and its ancillary documents do not specify the level of rigor and completeness of the analyses required of a potential applicant in order to obtain a license by the EPA. However, judging from the point of view of meeting the NRC 10 CFR 61 rule and DOE order 5820.2A, the BID analyses do not appear to have the same level of rigor and completeness as is expected of organizations which may be required to perform those analyses. In fact, because the EPA analysis does not address intruder protection scenarios, it would not meet the standards of a Nuclear Regulatory Commission ${ }^{6}$ or of a DOE review process. On the other hand, the BID indirectly calls for onsite intruder scenarios "...to be evaluated on a site specific basis" [BID, p. 8-12]. Human intrusion could disrupt infiltration barriers over disposed wastes, leading to higher doses to an offsite member of the public. Thus, because EPA did not consider the potential for intrudercaused disruption of a disposal facility, yet expects that intrusion be considered as part of a site-specific performance assessment, EPA appears to require analyses demonstrating compliance with a standard that are more stringent than the analysis in the BID.

6 The NRC rule expressly requires protection of individuals "...inadvertently intruding into the disposal site and occupying the site or contacting the waste at any time after active institutional controls over the disposal site are removed."|FR, 1982; 61.42) 
It can be speculated further, that, during a standard review process, the NRC would be likely to ask for a rnore complete evaluation of release pathways and a rationale for not taking into account leaching of the waste during the time of institutional control of the site. The rationale for treating the whole facllity as a single point source discharging to a distant well would also have to be substantiated.

Furthermore, compliance with CERCLA (Comprehensive Environmental Response Compensation and Liability Act) requirements may necessitate the simulation of the location of the CPG well at $1 \mathrm{~m}$ from the site boundary. This case is not addressed sufficiently by the EPA which, in its reference modeling assumption, located the well 100 $\mathrm{m}$ from the edge of the disposal site (actually about $260 \mathrm{~m}$ from the point source representing the leaking disposal site as explained in Section 1.2.2 of this report.)

Thus the EPA may have drafted a standard that requires an analysis which is more stringent than the analyses reported in the BID. It is not clear that more stringent analyses would still support the EPA standard's requirements.

\subsubsection{Code usage}

From the CPG code documentation, it appears that the application of the PRESTO family of codes was extended beyond their original intended usage. It is stated by the EPA that "The PRESTO-EPA codes were developed to assess and compare alternative methods for managing and disposing of $L L W$ at generic sites for general scenarios. The codes were not developed to analyze any specific sites." [CPG, p. x] Yet the EPA did extend the use of the codes to "... evaluate and support its decisions for the LLW standards." [CPG, p. 1-1] In fact, the dose limit criteria found in draft standard 40 CFR 193 were supported by analyses with the PRESTO codes.

Because the prescribed dose limits are supported by computer codes used outside their intended range, it is questionable whether those limits can actually be achieved with reasonably available technology and present disposal sites, unless the code is demonstrated to be conservative and defensible.

7 It is also likely that the closer the trench is to the CPG, the more significant gaseous exposure pathways become. 


\section{REVIEW OF EPA'S LEACH-AND-TRANSPORT MODELS}

The EPA analyses supporting the draft 40 CFR 193 consider a wide variety of release pathways: air, groundwater, rivers, streams, surface runoff, etc. Therefore the EPA codes rely on a combination of relatively simple models. Because a key set of models for predicting potential releases are the leach-and-transport models from the disposal trench, these have been reviewed for completeness and applicability to trench disposal methods. In particular, we shall examine in detail the bases of the EPA analyses in modeling the source inventory, the water infiltration into the trench, and the leach rates of radionuclides from the emplaced waste.

\subsection{Waste inventory}

The waste inventory estimates and projections used by the EPA in their CPG analyses are reported in Table I. A comparison between these data and the 1987 through 1989 inventory data on wastes buried at the commercial disposal sites [NRC, 1990] reveals that, for most radionuclides, the annual inventory estimated by the EPA (inventory in Table I divided by 20 years of operation) is 2-3 times higher than the 1987 through 1989 data. For $\mathrm{C}-14$, one of the most important radionuclides in determining maximum doses and health effects, the EPA estimated inventory, $294 \mathrm{Ci} / \mathrm{yr}$, is consistent with the commercial disposal data: $235 \mathrm{Ci}$ in 1987, $190 \mathrm{Ci}$ in 1988, and $372 \mathrm{Ci}$ in 1989.[NRC, 1990] However, the inventories of a few other significant radionuclides are underestimated. Namely:

a) EPA appears to be a factor of 10 low for Tc-99.

b) EPA appears to be two orders of magnitude low for U-238. EPA predicts $1.7 \mathrm{Ci} / \mathrm{yr}$, however, disposal at the coinmercial sites totalled $326 \mathrm{Ci}$ in 1987 and $348 \mathrm{Ci}$ in 1988. In these two years, $674 \mathrm{Ci}$ of $\mathrm{U}-238$ were disposed of as compared to the EPA estimate of $34 \mathrm{Ci}$ in 20 years.

c) EPA appears to ignore Th-232 [see also: BID, Table 3-4 and Table C-6]. The activity disposed of at the commercial sites was $409 \mathrm{Ci}$ in 1987 and 424 $\mathrm{Ci}$ in 1988. The environmental mobility of Th-232 is expected to be low; however, it is extremely toxic as measured by the ICRP annual limit for intake, ALI. (Th-232 ALI is more than a factor of 10 lower than for U-238).

d) EPA also appears to ignore $\mathrm{Kr}-85$ [see also: BID, Table 3-4 and Table C-6]. $\mathrm{Kr}-85$ is a gaseous element with no important attenuation during migration. It may have relatively quick transport times to the environment. In 1989, 193 Curies of $\mathrm{Kr}-85$ were buried at the commercial LLW sites. 


\section{TABLE I}

Wasteform radionuclide inventories expressed in curies (Table 6-5 in CPG).

\begin{tabular}{|c|c|c|c|c|c|}
\hline Muclide & $\begin{array}{l}\text { Absorbed } \\
\text { Matertal }\end{array}$ & $\begin{array}{l}\text { Act frated } \\
\text { Metals } \\
\end{array}$ & Trash & Solldifled & $\begin{array}{l}\text { Inct nerated } \\
\text { Soltdtfied } \\
\end{array}$ \\
\hline 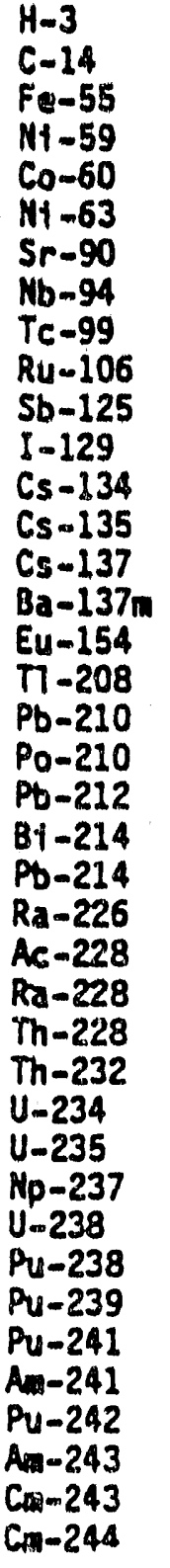 & $\begin{array}{l}5.20 E+03 \\
2.08 E+02 \\
4.04 E+04 \\
4.23 E+01 \\
7.34 E+04 \\
4.10 E+03 \\
4.08 E+02 \\
1.34 E+00 \\
2.73 E+00 \\
2.88 E+02 \\
5.49 E+02 \\
7.64 E+00 \\
7.23 E+04 \\
2.71 E+00 \\
7.23 E+04 \\
7.23 E+04 \\
5.50 E+01 \\
0.00 E+00 \\
6.74 E+00 \\
6.74 E+00 \\
0.00 E+00 \\
6.74 E+00 \\
6.74 E+00 \\
1.35 E+01 \\
0.00 E+00 \\
0.00 E+00 \\
0.00 E+00 \\
0.00 E+00 \\
2.30 E+00 \\
3.68 E-02 \\
4.23 E-03 \\
6.72 E-01 \\
6.47 E+01 \\
4.19 E+01 \\
1.79 E+03 \\
9.35 E+01 \\
8.64 E-02 \\
2.68 E+00 \\
2.91 E+00 \\
3.57 E+01\end{array}$ & $\begin{array}{l}2.17 E+04 \\
4.74 E+01 \\
4.06 E+05 \\
2.53 E+02 \\
2.93 E+02 \\
3.49 E+04 \\
2.49 E+03 \\
1.49 E+00 \\
0.00 E+00 \\
0.00 E+\infty 0 \\
0.00 E+00 \\
0.00 E+00 \\
0.00 E+00 \\
0.00 E+00 \\
2.94 E+04 \\
2.94 E+04 \\
0.00 E+00 \\
0.00 E+00 \\
7.07 E+01 \\
7.07 E+01 \\
0.00 E+00 \\
7.07 E+01 \\
7.07 E+01 \\
7.07 E+01 \\
0.00 E+00 \\
0.00 E+00 \\
0.00 E+00 \\
0.00 E+00 \\
0.00 E+00 \\
0.00 E+00 \\
0.00 E+00 \\
0.00 E+00 \\
5.88 E+01 \\
0.00 E+00 \\
0.00 E+00 \\
9.72 E+01 \\
0.00 E+00 \\
0.00 E+00 \\
0.00 E+00 \\
0.00 E+00\end{array}$ & $\begin{array}{l}1.78 E+05 \\
4.42 E+02 \\
7.40 E+03 \\
7.42 E+00 \\
1.41 E+04 \\
2.11 E+03 \\
8.03 E+04 \\
2.35 E=01 \\
9.41 E-02 \\
1.68 E+02 \\
9.62 E+01 . \\
2.54 E-01 \\
2.89 E+03 \\
9.46 E-02 \\
7.93 E+03 \\
7.93 E+03 \\
9.64 E+00 \\
0.00 E+00 \\
0.00 E+00 \\
0.00 E+00 \\
0.00 E+00 \\
0.00 E+00 \\
0.00 E+00 \\
0.00 E+00 \\
0.00 E+00 \\
0.00 E+00 \\
0.00 E+00 \\
0.00 E+00 \\
1.53 E+00 \\
3.84 E-02 \\
5.73 E-03 \\
5.02 E-02 \\
4.86 E+00 \\
4.90 E+00 \\
2.14 E+02 \\
6.0 \pi E+01 \\
1.07 E-02 \\
1.93 E-01 \\
2.59 E-03 \\
2.17 E+00\end{array}$ & 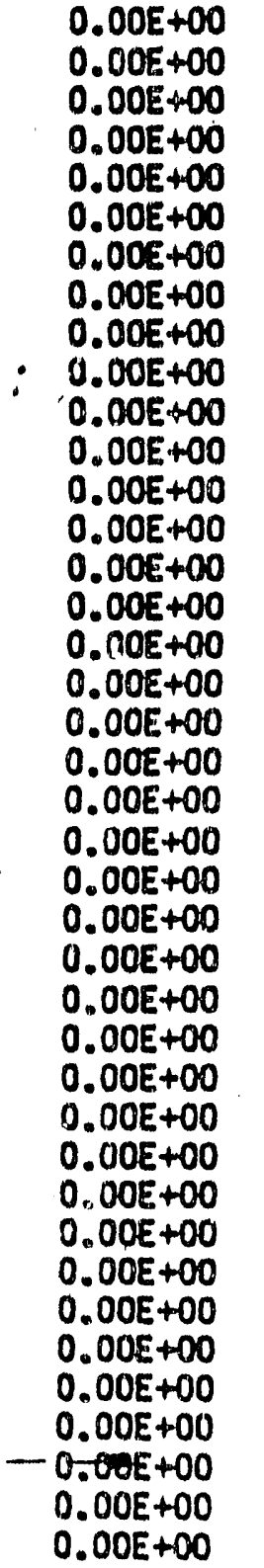 & $\begin{array}{l}0.00 E++0 \\
0.00 E+00 \\
0.00 E+00 \\
0.00 E+00 \\
0.00 E+00 \\
0.00 E+00 \\
0.00 E+00 \\
0.00 E+00 \\
0.00 E++0 \\
0.00 E+00 \\
0.00 E+00 \\
0.00 E+00 \\
0.00 E+00 \\
0.00 E+00 \\
0.00 E+00 \\
0.00 E+00 \\
0.00 E+00 \\
0.00 E+00 \\
0.00 E+00 \\
0.00 E+00 \\
0.00 E+00 \\
0.00 E+00 \\
0.00 E+00 \\
0.00 E+00 \\
0.00 E+00 \\
0.00 E+00 \\
0.00 E+00 \\
0.00 E+00 \\
0.00 E+00 \\
0.00 E+00 \\
0.00 E+00 \\
0.00 E+00 \\
0.00 E+00 \\
0.00 E+00 \\
0.00 E+00 \\
0.00 E+00 \\
0.00 E+00 \\
0.00 E+00 \\
0.00 E+00 \\
0.00 E++00\end{array}$ \\
\hline
\end{tabular}


e) EPA appears to be low by a tactor of 3.5 for Ra-20. Also, the inventory data for disposal at commercial LLW sites in the vears 1987-1989, indicate that over one half of the $R_{2} \cdot 20$ was disposed of in unstabilized, Class $A$ wastes. This contrasts with the EP.'s assumptions as indicated in Table I, whereby over $80{ }^{\circ}$ of the inventory of this radionuclide is thought to be retained in activated metals. Ra- 20 may be especially important because one of its daughters. Rn- $m$, is a noble gis having high mobility in unsaturated soils.

f) EPA does not treat ingrowth of radionuclide daughters conservatively. ${ }^{8}$ For example, the decay chain of $\mathrm{Ra}-226$ includes $\mathrm{Rn}-222$ and $\mathrm{Pb}-210$. Given enough time, these nuclides will reach secular equilibrium with $\mathrm{Ra}-226$. Because the half-life of $R_{2}-20$ is 1600 years, there will be a substantial supply of its daughters tor thousands of years. EPA does recognize ingrowth will occur and sets the initial inventory of $\mathrm{Pb}-210$ to $\mathrm{l} / 2$ the value of $\mathrm{Ra}-226$. However, without accounting for ingrowth, Pb-210, half-life of $22.3 \mathrm{yrs}$, decays to a few percent of its initial inventory in 100 years. If ingrowth is accounted for. the activity of $\mathrm{Pb}-210$ at 100 years is approximately that of $\mathrm{Ra}$ 226.

Another poterntial problem with the EPA inventory estimate is that they ignore the volume, activity, and radionuclide composition of DOE-generated waste. Nuclide inventories and waste characteristics of DOE LLW are significantly different from commercial LLW. Over the past 10 years, the disposal of DOE waste has far exceeded that of the commercial sector.

\subsubsection{Source homogenization}

The EPA homogenized the national inventory data for commercial waste over 12 disposal sites. In this scenario all sites receive the same radionuclide distribution, volume, and curie content. Currently, however, there are major differences between the waste received at the three operating sites. The differences between the national average and what actually reaches a disposal site are likely to become larger as the State Compacts begin to dispose of waste. This is due to the relatively large number of compacts and to the diversity of waste-producing activities between the compacts.

These observations suggest that any generic analysis of potential releases from disposal sites should take into account a realistic range of radionuclide inventories to be disposed of as well as a realistic range of radionuclide compositions, including DOE-generated LLW. The analyses performed by the EPA appear to be lacking in this respect.

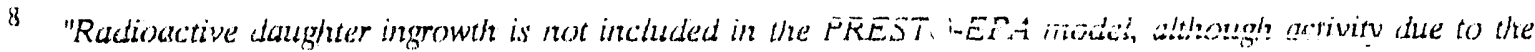
daighters can be accounted for by direct input of the daughter source term." [BID, p. 8-2] 


\subsection{Water infiltration model}

\subsubsection{Intact trench caps}

Water infiltration through an intact trench cover is estimated from the model by Hung [POP, Appendix A]. Its complexity far surpasses any of the other water balance models used in the PRESTO family of codes.

Hung's approach "involves the modeling of three flow systems: an overland flow system, a subsurface flow system, and an atmospheric diffusion system. The overland flow system receives the rainwater and diverts the excess water from percolation and evaporation into the receiving drainage system. ${ }^{9}$ The subsurface flow system receives the percolated water from the overland fle "system and transports the water either downward as infiltration into the trench and/or upward as evaporation into the atmospheric diffusion system. The atmospheric diffusion systems (sic) receives water/vapor from the overland flow system or subsurface flow system and transports the vapor to the atmosphere. " [POP, p. A-1] The system of equations eventually implemented by Hung "cannot simulate the dynamic response of soil moisture as precisely as the original differential equations" [POP, p. A-27]; however, as far as predicting the cumulative amount of water infiltrating the trench, the model appears to have reasonable accuracy for application to a site in a humid zone. ${ }^{10}$

It is not clear that the model can simulate situations whereby the transport of soil moisture is not dominated by liquid phase transport. For instance, when the groundwater table is more than a few meters deep, the rate of evaporation may be dominated by the vapor phase transport in the subsurface. "There are no data available for evaluating the transport of pellicular water in a vapor phase." [POP, p. A-21] At the same time there are researchers who feel that there is no single acceptable method to calculate infiltration at both humid and arid sites [Gee, 1988].

The estimation of infiltration requires subtraction of the evapotranspiration and surface run-off from the precipitation. At arid sites, these numbers are large relative to the result of the subtraction. Therefore small errors in estimating these parameters may lead to large errors in predicted infiltration. The EPA provides no estimate of these errors.

9 Interestingly, the EPA documentation neither defines what a drainage system consists of nor presents a model for its performance over the years. Potential consequences of the drainage system failure, e.g., ponding, do not appear to be accounted for.

10. "When the model was applied to the Barnwell radioactive waste disposal site, the results of the sintulation fit very well with the results of analysis conducted by other investigators using the (sic) other methods." [POP, p. A-27] The Barnwell site, however, is characterized by a fairly substantial rainiall of $118 \mathrm{cr} / \mathrm{yr}$ and any pellicular water deficit is conlined to the top portion of the trench. 


\subsubsection{Failed trench caps}

The volume of water entering a trench in a given year is defined as the sum of the volume infiltrating the intact portion of the trench cover and of the volume of rainwater that falls on the damaged portion of the trench cap [POP, p. 2-5].

Due to their function as barriers to meteoric water, intact trench caps are designed to have low permeability and to allow relatively little water to infiltrate the trench. Thus, as rainwater can penetrate unimpeded failed portions of the trench caps, the user-supplied failed cap percentages tend to dominate the water balance in the trench. Indeed, water infiltration through the failed portion of the caps appears to be the only meaningful mode of infiltration at the arid site (southwest site) and at the humid impermeable site (northeast site). ${ }^{11}$ Thus, because the code user must supply:
a) the beginning and ending years of trench cap failure
b) the beginning and final percentages of cap failure
c) the yearly rainfall on the site

it appears that, from a practical point of view, the total amount of water infiltrating a trench every year is determined a priori, without supporting data, by the code user. This is especially true at the arid and at the humid impermeable sites.

It is not clear to these reviewers the extent to which the EPA's assumptions about the failure percentages were supported through an effort to determine those values through a subjective, probabilistic analysis (data obtained from experts' polls, for instance, coupled with an analysis of actual trench caps failure data) or through an analysis demonstrating that the predicted results are conservative. It is clear however that, in the absence of such analyses, much controversy about the assumed values will exist and that, indirectly, future license applicants may feel encouraged to refer themselves to those same data and code models, not because they are well supported, but because they were used by the EPA.

11 Regular infiltration through the non-cap portion at the reference arid site (the southwest site) was asisumed to be zero [Rogers, 1985, Table 5.1]. Thus, it is likely that the infiltration through the capped portion of the site was also modeled to be zero. Therefore, it appears that, at the arid site, all water entering the trench is because of trench cap failure. Similarly, at the impermeable site (northeast site) infiltration in the non-capped portion of the site is extremely small $(0.003 \mathrm{~m} / \mathrm{yr})$ [RAE, 1985; Table 5.1 . 


\subsection{Leaching models}

Leach rates are computed on a yearly basis. Leaching from solidified wastes is modeled in terms of radionuclide-independent and environment- and wasteform-dependent leach factors which are constant in time. A leach factor represents the fracticnal amount of the total radionuclide inventory which is leached in a year. The leached-out yearly fraction from solidified waste is added to the radionuclide inventory present at the beginning of the year in the so-called "absorbing materials" (non-solidified waste, basically) and in the trench water. The new inventory represents the radionuclide fraction that can actually leave the trench that year. In turn this is partitioned between the waste surfaces and the groundwater through a $\mathrm{K}_{\mathrm{d}}$ approach. The resulting solute concentration in the groundwater is then further modified by multiplying it by the fraction of the year during which standing water is present in the trench and is ahle to wet the waste.

It is readily seen that the leaching model is entirely empirical. Also, no attempts appear to have been made to validate it. As is the case for all empirical models, it may yield conservative or non-conservative results in a given year depending on the values of the parameters that are used. Some modeling hypotheses that would contribute to nonconservatism of the predictions are explored hereafter.

\subsubsection{Fractional contact time}

In the definition of the solute concentration in the trench water, $\mathrm{C}_{\mathrm{T}}$, the yearly, fractional water-waste contact time, TCON, a dimensionless number less than 1 , appears in the numerator. Namely:

$$
C_{\mathrm{T}}=\frac{I_{\mathrm{T}} f_{\mathrm{W}} C F F \quad T C O N}{V_{\mathrm{T}}}
$$

with:

$\left(I_{T} f_{W} C F F\right)$ the radionuclide inventory available for release

$\mathrm{I}_{\mathrm{T}}$, the radionuclide inventory in the trench

$f_{W}$, the fraction of total waste immersed in water.

CFF, a time-dependent, user-supplied factor for the fractional amount of failed contairers, and

$\mathrm{V}_{\mathrm{T}}$, the effective volume of standing water in the trench adjusted for sorption effects. 
Thus, in Equation (1), TCON effectively reduces the available inventory for release yielding in turn a smaller solute concentration value. ${ }^{12}$ On the other hand, since

(a) by dofinition, concentration of a solute is simply the amount of solute (radionuclides, here) divided by the volume of solvent (water in this case), and

(b) the code determines on a yearly basis the volume of standing water collecting in the trench and the amount of radionuclides available for release in a year,

there seems to be no need for the quantity TCON to appear in Equation (1).

Furthermore, although the EPA codes require a standing body of water in the trench to calculate the leach rates, it must be pointed out that the moisture content of the soil may be sufficient for leaching of the waste. There will always be some degree of moisture present in the trench soil. Thus, for practical purposes, the contact time can be $100 \%$ if soil surrounds the waste form.

Leaching of nitrate from saltstone has been shown to be independent of the degree of saturation down to the residual moisture content of the soil [Wilhite, 1987; Oblath, 1989]. Also, a recent paper examined the leach rate of barium-133 tagged vermiculite (an absorbing material) under controlled, unsaturated flow conditions [Eicholz, 1990]. Although "The relative release rate obtained at $0.36 \mathrm{~cm}^{3} / \mathrm{cm}^{3}$ (39\% saturation) was $40 \pm 4 \%$ of the saturcted leach rate. At $0.71 \mathrm{~cm}^{3} / \mathrm{cm}^{3}$ (77\% saturation) the leach rate was back to $108 \pm 8 \%$ of the saturated rate." [Eicholz, 1990].

Wet/dry cycle leach experiments are the ones that most closely simulate the influence of contact time on leaching. Available experimental data collected by [Arora, 1986] have not shown a direct dependence of leaching on contact time. Arora examined the releases from ion exchange resins solidified in cement waste forms surrounded by a porous medium, for fixed durations of wet and dry periods. During the dry periods there was essentially no moisture around the waste form. However, the releases far exceeded that from a totally saturated system multiplied by the contact time. The measured releases are best explained by assuming that during the dry period diffusion occurs within the wasteform thereby bringing mass closer to the surface for its eventual release [Sullivan, 1990]. Experimental evidence for the redistribution of the constituents of the pore water in cement during dry periods has been observed [Fuhrmann, 1989].

12 The yearly, fractional, water-waste contact time is calculated as the ratio of the infiltration rate (m/yr) through the uncapped portion of the site by the permeability of the trench. Using typical values for both the humid sites [PEI, Table 5.1] leads to a TCON of 0.16-0.2, i.e., a reduction in leaching greater than a factor of 5 . At the arid site the meaning of the contact time is not clear because the assumed infiltration rate is zero. 


\subsubsection{Trench $K_{d}$ 's}

"A key option in PRESTO utilizes the mechanism in which the waste is in contact with water in the trench for a sufficiently long time that an "equilibrium" or "quasi-equilibrium" condition exists between the concentrations of the nuclides in $t .$. trench water and in the solid waste in the trench." [RAE, 1984; p. 1]

"Trench $K_{d}$ 's", also referred to as "waste $K_{d}{ }^{\prime} s$ ", are radionuclide and environment dependent [Table II]. The $\mathrm{K}_{d}$ for the humid permeable setting were obtained by:

(a) taking measured, average radionuclide concentrations in trench leachate, $[\mathrm{pCi} / \mathrm{ml}$-water], at Maxey Flats,

(b) estimating the total amount of radionuclides sorbed on solid materials present in the trench,

(c) estimating the total mass of solid materials in the trenches, and

(d) dividing the isotopic concentrations on the solid materials, [pCi/gsolid], by the average concentration in the trench water.

Even assuming that item (a) provides defensible data, item (b) points out an inherent inconsistency in the $K_{d}$ estimating approach, in that the final $K_{d}$ 's will be an artifact of the assumption made in estimating the total inventory in a trench. In the EPA modeling approach, which homogenizes waste and soil, one would have to know before hand either the $\mathrm{K}_{\mathrm{d}}$ itself or the initial radionuclide inventory and the subsequent trench losses up to the time when the solute concentration was measured ${ }^{13}$. Item (c) will also be fraught with considerable uncertainty.

An indication of the low degree of reliability of the above procedure for estimating $\mathrm{K}_{\mathrm{d}}$ 's, comes from the observation that "For tritium in trenches 1, 7,27, and 37 the activity in the leachate exceeded the inventory, assuming complete trench saturation." [RAE, 1984; p. ib]. Conversely "For cobalt, several of the ratios are unrepresentatively low and have been conservatively discarded assuming that they represent disposal trenches containing a significant amount of sealed sources in the inventory." [RAE, 1984; p. 1b]

Although all $\mathrm{K}_{\mathrm{d}}$ 's estimated by the above procedures are suspect, the reference document [RAE, 1984] singles out only a few as being potentially non-conservative. Thus, it is suggested, withnut justification, that, for the most mobile radionuclides, such as $\mathrm{H}-3$, C-14, Tc-99, I-129, and Np-237, PRESTO should utilize soil $\mathrm{K}_{\mathrm{j}}$ 's rather than the calculated

13 In other words, for obtaining a $K_{d}$ value, it takes the determination of two cxperimental quantities: the concentration in the leachate and the concentration on the solid mass. The authors of [RAE, 1984] try to make do with the experimental determination of only one of those quantities. 
马

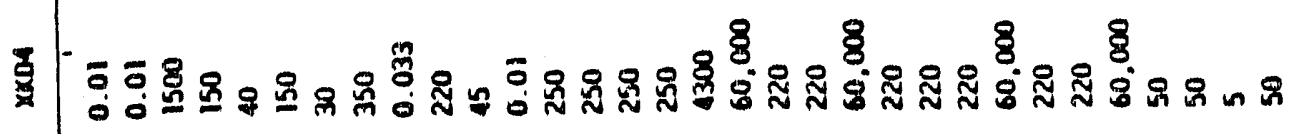

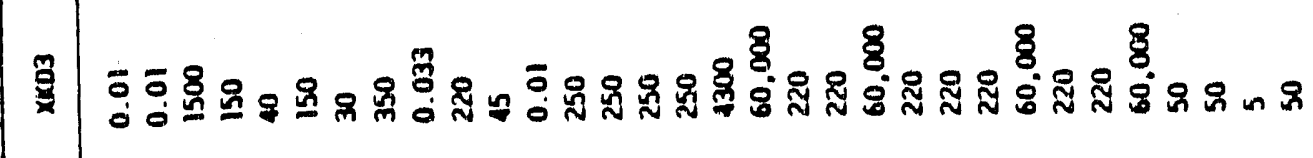

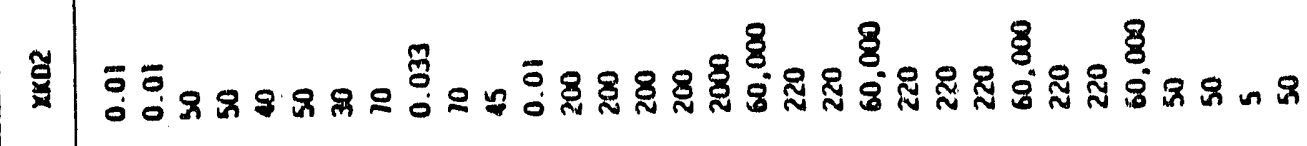

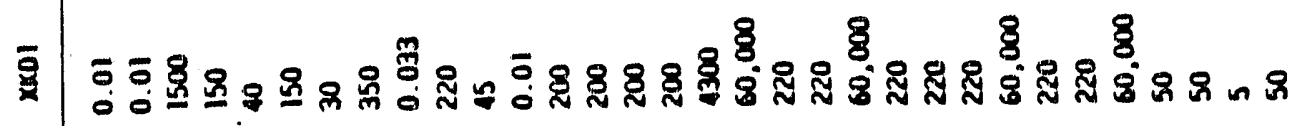

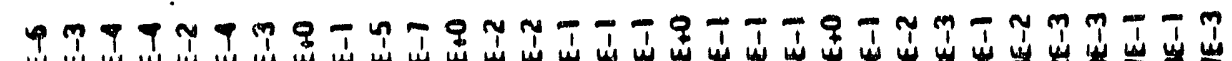

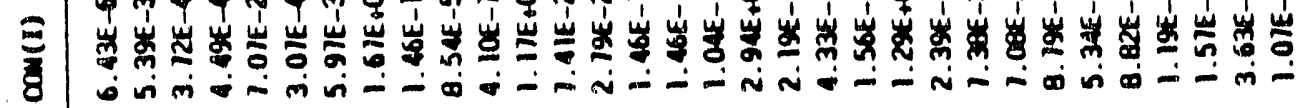

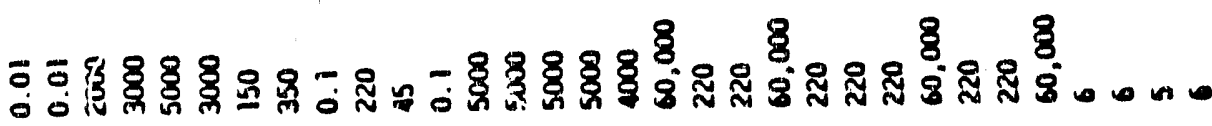

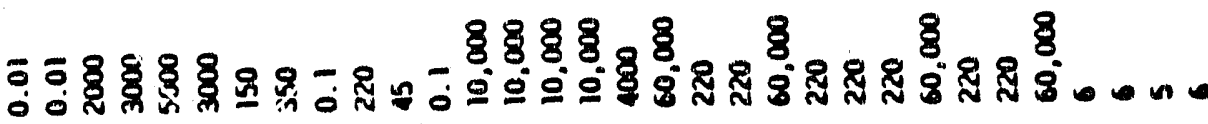

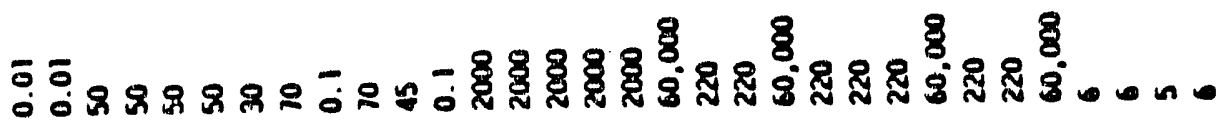

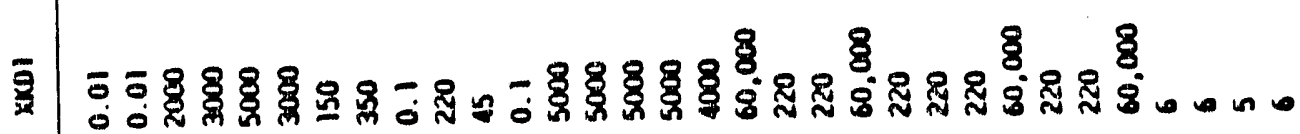

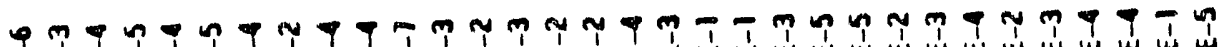

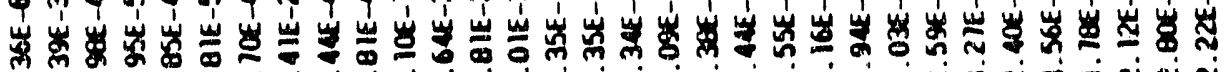
内人 ⿰亻门

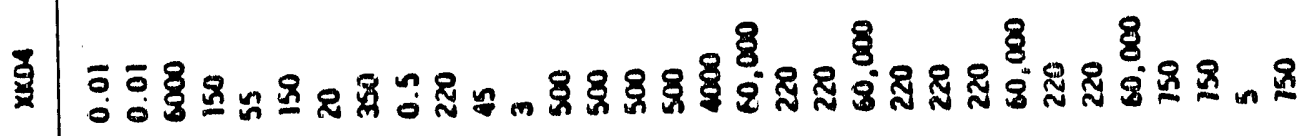

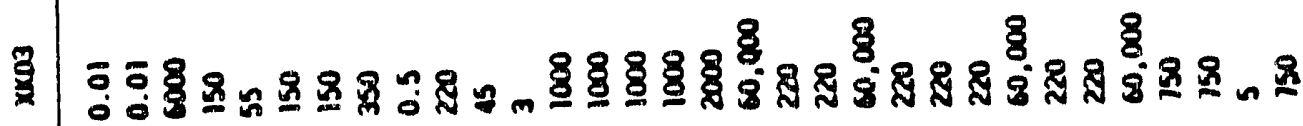
○西 范

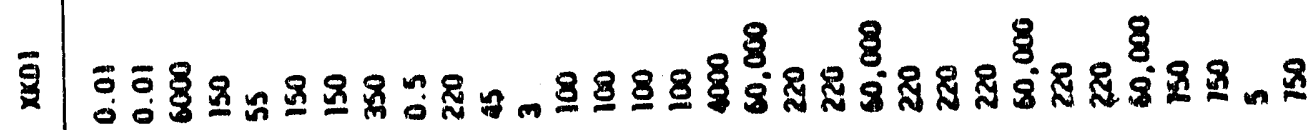
$\frac{8}{\frac{8}{3}}$ n=药

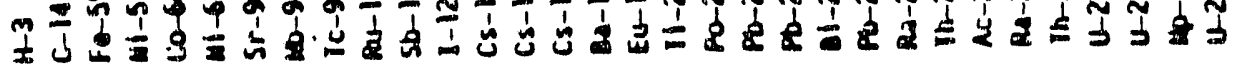




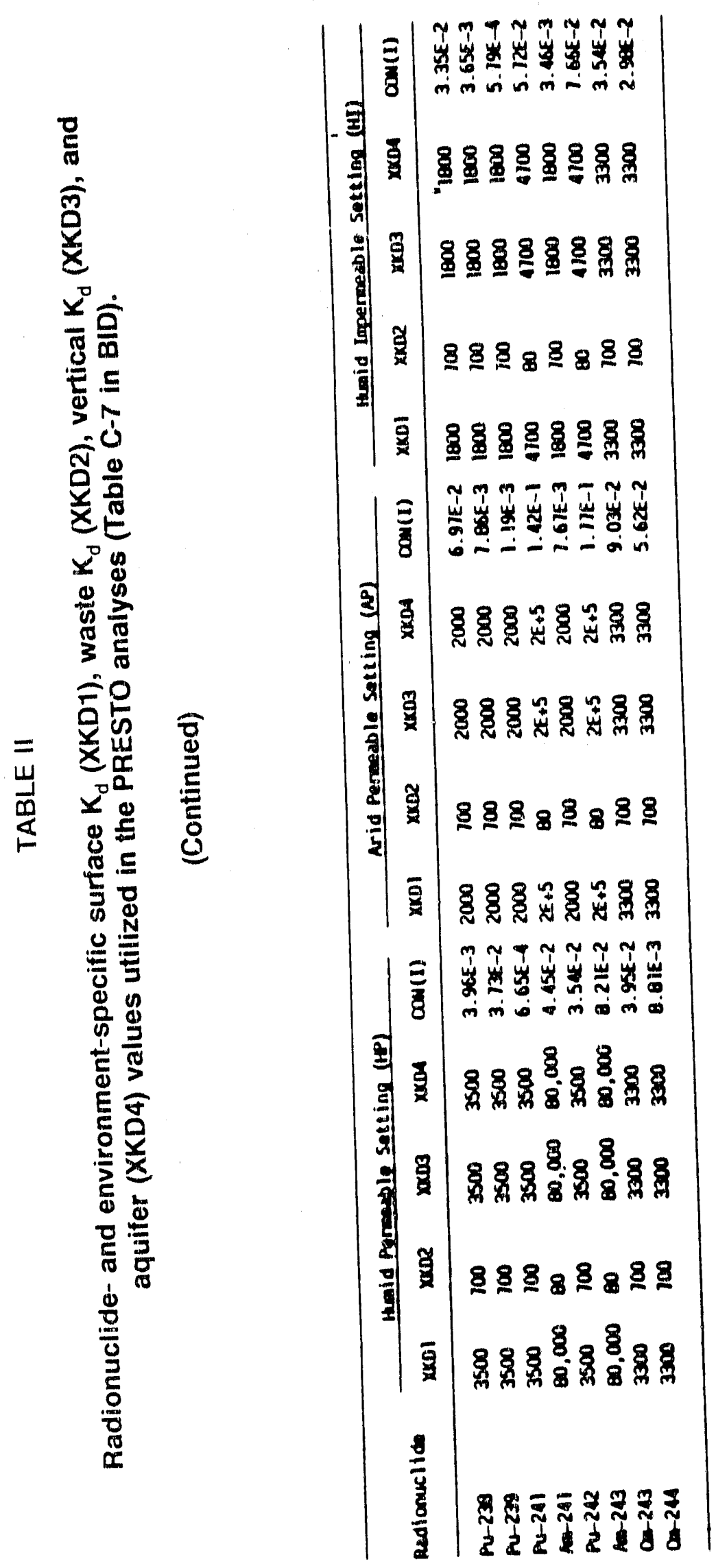


trench $\mathrm{K}_{d}$ 's. As an example, the $\mathrm{K}_{d}$ for $\mathrm{Np}-237$ is thus reduced from a calculated trench value of 700 to a soil value of 5 . On the other hand, the trench $K_{d}$ for plutonium and curium was taken as 700 with the justification that "neptunium and curium are chemically similar to plutonium and also have the same $K_{\mathrm{d}}$ value." [RAE, 1984; p. 6] That is, for these nuclides the trench $\mathrm{K}_{d}$ value of 700 is kept in PRESTO [CPG, p. 6-8].

The trench $\mathrm{K}_{\mathrm{d}}$ for $\mathrm{U}-238$ estimated through the above procedure ${ }^{14}$ was 3,000 [RAE, 1984 ; p. 7]. The PRESTO codes implement the more conservative value of 750 , without justification. The radium $\mathrm{K}_{\mathrm{d}}$ value was "estimated to be a factor of seven less than uranium" [RAE, p. 6], yet its PRESTO value is 220.

In sum, considering also that the $\mathrm{K}_{d}$ concept is valld only when the sorption sites are not fully occupied and that $K_{d}$ values vary for different types of soils and soil conditions (including $\mathrm{pH}$, presence of chelating agents, etc.), the assumed trench $\mathrm{K}_{\mathrm{d}}$ values for the humid permeable site are highly uncertain. They may or may not result in conservative predictions depending on the site and the chemical element under study.

We have not reviewed clocuments giving the rationale for the assumed, trench $\mathrm{K}_{\mathrm{d}}$ values at the arid and at the humid impermeable sites. Because of the above observations, which are very general, it is likely that these also will be affected by a large degree of uncertainty.

\subsubsection{Leach factors}

\subsubsection{Time dependence}

The EPA analyses assume that the leach rates for solidified wastes are constant in time. There exists, however, a large body of literature wh ch suggests that leaching from wastes solidified in cement, vinyl esther- styrene (VES), and bitumen can often be explained as a diffusion process with release rates initially proportional to (time $)^{-0.5}$. Diffusion releases are characterized by relatively high release rates at earlier times [Figure 4]. If these rates exceed the EPA leach rate factors over long periods of time, it will have great significance in predicting peak doses to the CPG.

The cumulative, fractional diffusive release from a cylindrical waste form of radius 28.5 $\mathrm{cm}$ and height $85 \mathrm{~cm}$ (55 gallon drum) with an effective diffusion coefficient of $10^{-8} \mathrm{~cm}^{2} / \mathrm{s}$ would reach $4.4 \%$ in the first year; $13.7 \%$ in 10 years; $40 \%$ in 100 years; and $93 \%$ in 1,000 years. Using a constant leach fraction of $10^{-3} \mathrm{yr}^{-1}$, the highest leach rate used by the EPA, would release $100 \%$ of the contaminant in 1,000 years, however, it would allow only $0.1 \%$ out in the first year, a factor of 40 lower than predicted by the diffusion model. Figure 4 illustrates that diffusion controlled release rates can exceed the maximum EPA release rate by orders of magnitude for hundreds of years depending on the diffusion coefficient. If

14 For this radionuclide the leachate data were taken from West Valley; the waste inventory data from Maxey Flats. 


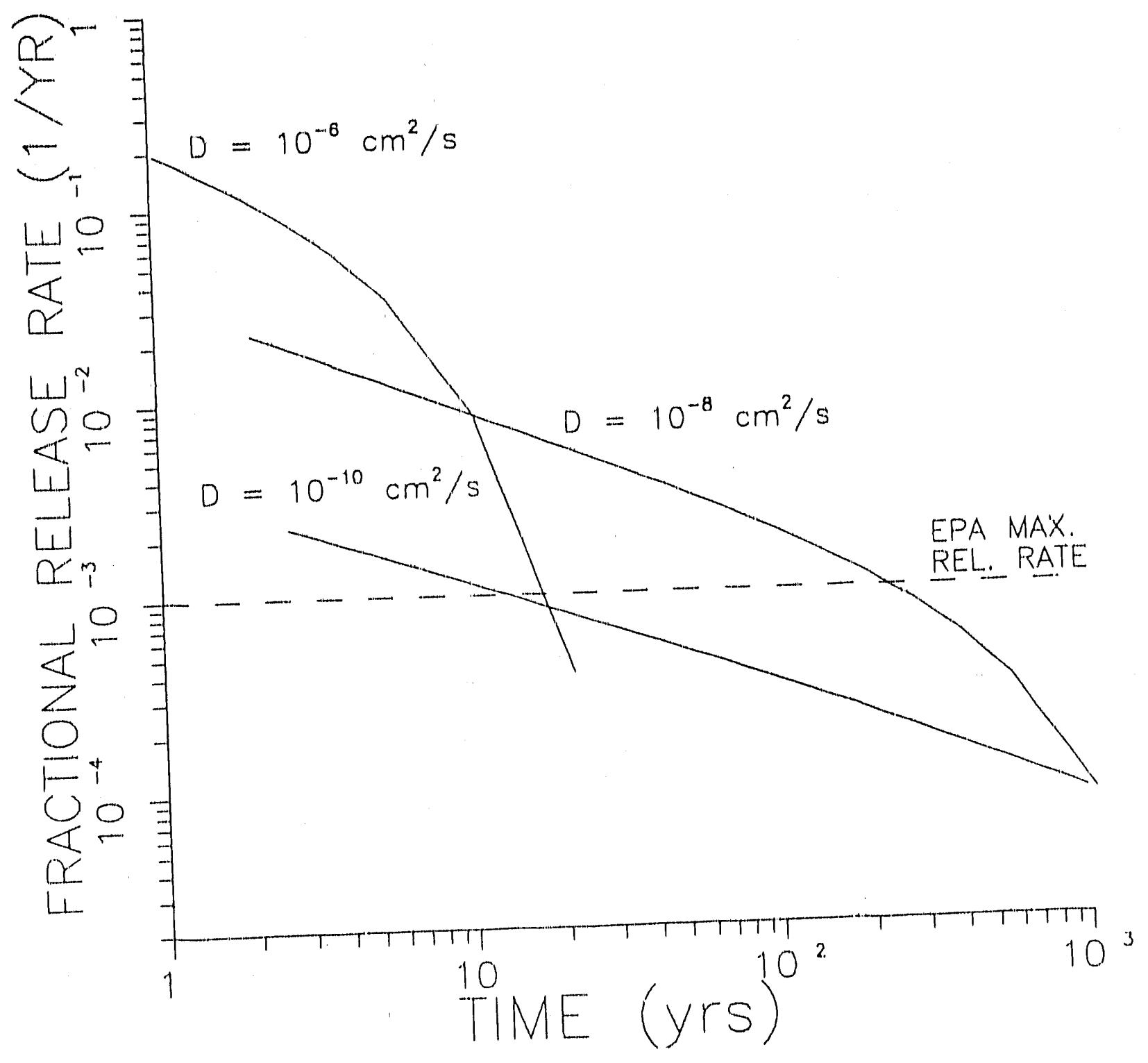

Calculated fractional release rates from a 55-gallon drum wasteform based on diffusion. For diffusion coefficients greater than $10^{-8} \mathrm{~cm}^{2} / \mathrm{s}$, the release rates fall below the maximum rate assumed by the EPA only when the wasteform is significantly depleted. Typically, important radionuclides such as ${ }^{3} \mathrm{H},{ }^{129} \mathrm{I}$, and ${ }^{137} \mathrm{Cs}$ have diffusion coefficients comparable or greater than $10^{-8} \mathrm{~cm}^{2} / \mathrm{s}$. 
diffusion is the rate controlling release mechanism, EPA would have to alter its models or use rate constants that could be shown to give conservative predictions at all times.

\subsubsection{Dependence on specific radionuclides}

Normally, leaching is not a process whereby all radionuclides are released at the sarne rate. Tritium release from cement wasteforms, for instance, is much faster than the release of strontium or uranium, say. Thus, the congruent release assumption implemented by the EPA, may lead to results which are conservative for some radionuclides and non. conservative for others. In general, if radionuclide-independent leach factors are used, their values should be selected to give conservative or realistic results with respect to the fastest leaching radionuclide for the wasteform and the surrounding environment under study. ${ }^{15}$

\subsubsection{Dependence on infiltration rates}

For the same waste forms, the EPA analysis utilizes leach factors values which are lower for arid sites than for humid sites. On the other hand, since leaching is assumed to take place only when a wasteform is in contact with trench water, the leach factors should be the same regardless of the enviranmental conditions of the site where wetting occurs.

This internal inconsistency within the PRESTO codes may cause artificially small releases at the arid sites.

\subsubsection{Dependence on disposal method}

Because leach factors are deemed infiltration-rate dependent (Section 3.3.3.3), and because different disposal methods may allow different infiltration rates under the same environmental conditions, leach factors are also implemented as being disposal-method dependent [RAE, 1985; p. 3-1]. ${ }^{16}$

15 It is important to point out that, since tritium is very mobile both in solidified waste and in the groundwater, the EPA analyses might have grossly underpredicted its contribution to the peak dose to the CPG. This is especially true if the path to the drinking well were not as long as it was modeled, if underground releases were allowed to start before the end time of institutional control of the site, and if airborne releases are accounted for.

16 "Annual leach fractions between $10^{3}$ and $10^{-4}$ are applicable to the bulk of the measured data. Therefore, a value of $4 \times 10^{-4}$ per year was selected for CSD at the SE and NE sites. Because ISD has a lower infiltration rate, a leach fraction of $2 \times 10^{-4}$ is used for this alternative." 
This assumption represents a further exacerbation of the influence of infiltration rates on leach fractions which has been questioned already (Section 3.3.3.3).

\subsubsection{Releases from activated metals}

A great part of the activated metals are stainless steels and Zircaloys. Typical corrosion rates for types 304 and 316 stainless steel in soil environments range from $5.7 \cdot 10^{-5}$ to $2.8 \cdot 10^{-8} \mathrm{~cm} / \mathrm{yr}$ with a mean value of $2 \cdot 10^{6} \mathrm{~cm} / \mathrm{yr}$ [Gerhold, 1981]. Carbon steel, a common waste container material, exhibits corrosion rates ranging from $1.9 \cdot 10^{-2}$ to $8.5 \cdot 10^{-4}$ $\mathrm{cm} / \mathrm{yr}$ with a mean value of $5.7 \cdot 10^{-3} \mathrm{~cm} / \mathrm{yr}$ [Romanoff, 1957]. "Thus it would take a mean thme value of 1,000 years to corrode a $5.7 \mathrm{-cm}$ thick carbon steel specimen. It would take less (more) time for a thinner (thicker) specimen.

While PRESTO-EPA-POP combines the release fractions from activated metals with these of solidified waste [BID, Table C-8], PRESTO-EPA.-CPG relies on separate inputs for these waste categories [CPG, p. 3-2 through 3-3]. Suggested release fractions for activated metals are available in a report by Rogers and Associates [RAE, 1985]. The suggested leach fractions are in the range between $10^{-4}$ and $10^{-6}$ per year, implying that these waste forms will exist for 10,000 to $1,000,000$ years, regardless of their original thickness. Although it is not clear that these values were actually implemented in the CPG dose calculations, it is clear that these assumed leach fractions can be conservative for some metals and some specimen thicknesses and non-conservative for others. In the absence of an analysis that justifies these leach fractions, the assumed values must be regarded as suspect.

Furthermore, for surface processes such as corrosion, the fractional release rate will remain constant only as long as the surface area is constant. The surface area will not remain constant for curved surfaces unless the thickness of the metal is much smaller than the radius of curvature of the surface.

\subsubsection{Reference data base}

The basis for a constant, nuclide-independent, annual fractional release rate of $10^{-3}$ to $10^{-4}$ per year is found in a report by Rogers [Rogers, 1985; p. 3-1] which states "For the solidified waste, measured leach rate values for improved cement /Colombo, 1979a, 1980; Morcos, 1980; Kibbey, 1979; Christiansen, 1981; and Stone, 1977/, polymers [Neilson, 1979; 1980/, and bitumen /Neilson, 1979; Colombo, 1979/ were converted to fractional annual releases assuming the waste is contained in 55-gallon drums." We have obtained all of these documents for review. None of these reports make any direct statement that a radionuclideindependent fractional release rate of $10^{-3}$ per year is a reasonable value.

In the reports by Colombo and Morcos, release is believed to be controlled by diffusion processes with relatively high initial release rates that decrease in time. Based on their experimental data, these authors estimate that the cumulative release from a 55 gallon cement drum after 100 years of leaching for Cs would range from 17.9 - 19\%; for Sr the range is 32-38\%; and for $\mathrm{Co}$ the single estimated value is $0.3 \%$ [Colombo, 1979, Table 27]. 
For $\mathrm{Cs}$ and $\mathrm{Sr}$ this cumulative release would support a release rate that is a factor of 2 to 3 higher than the maximum fractional release rate assumed by EPA, $10^{-3} \mathrm{yr}^{-1}$. Also, release is strongly nuclide dependent. Further, the data indicate that release in the flrst year of leaching would be on the order of a few percent for $\mathrm{Cs}$ and $\mathrm{Sr}$. The high initial release rate is important for all radionuclides and most important for short-lived radionuclides. Similar calculations were reported for the 55 gallon drum size VES waste forms. In this case, the estimated 100 year release was $15 \%$ for $\mathrm{Co}$, and $5 \%$ for Cs and $\mathrm{Sr}$. Although a simllar calculation was not performed for bitumen waste forms, data presented in Fig. 18 of the report [Colombo, 1979] show cumulative fractional releases similar to the fractional releases measured for $\mathrm{Cs}$ and $\mathrm{Sr}$ from cement waste forms. Based on this one would expect the cumulative release after 100 years from a bitumen waste form in a 55 gallon drum to be approximately the same as that of the cement waste forms. However, it is known that bitumen waste forms often exhibit "... a tendency to swell, crack, and break up during leaching" [Colombo, 1979]. This swelling behavior leads to timendependent release characteristics which show a marked increase in release rate after swelling [Colombo, 1979].

The papers by Kibbey, Christiansen, and Nellson report the following leach rates from bitumen, cement, and VES:

\begin{tabular}{|c|c|c|c|}
\hline & Kibbey & Christiansen & Neilson \\
\hline & $\left(\mathrm{g} / \mathrm{cm}^{2} / \mathrm{d}\right)$ & $\left(\mathrm{g} / \mathrm{cm}^{2} / \mathrm{d}\right)$ & $\left(\mathrm{g} / \mathrm{cm}^{2} / \mathrm{d}\right)$ \\
\hline Bltumen & $10^{-1}-10^{-4}$ & $10^{-1}-4 \cdot 10^{-6}$ & $10^{-1}-10^{-7}$ \\
\hline Cement & $10^{-1}-10^{-4}$ & $2 \cdot 10^{-4}-3 \cdot 10^{-7}$ & $10^{-1}-10^{-7}$ \\
\hline VES & $10^{-2} \cdot 10^{-3}$ & -..m & $10^{-3}-10^{-5}$ \\
\hline $\begin{array}{l}\text { Resins Solidified } \\
\text { in Cement Gel' }\end{array}$ & $\ldots$ & $9 \cdot 10^{-7}-10^{-9}$ & $\ldots$ \\
\hline
\end{tabular}

- Experimentally measured for Cs solidified in cement gel. The range is due to different sorptive additives in the gel. $\mathrm{Cs}$ loadings up to $5,000 \mathrm{Cl} / \mathrm{m}^{3}$ were used.

The range of values found in these reports is so large that a very wide range of fractional release rates can be postulated. In the report by Neilson, the leach rate is stated to apply to alkali and alkaline earth elements. The report by Christiansen claims the leach rate given is for Cs. The report by Kibbey does not specify which elements the leach rate applies to.

Interestingly, Christiansen considers diffusion as the dominant release mechanism. The disposal system contains ion-exchange resins solidified in cement. Calculations of releases show peak release rates on the order of $2 \%$ per year. 
The [Stone, 1977] report examines the incorporation of simulated, DOE waste sludge into concrete and evaluates strontlum and cesium leaching over a 42-day period for several cement types and waste loadings. "The magnitude of cesium leachability values for concrete waste forms containing cesium-loaded zeolite were comparabie to those of strontium leachability from concrete containing sludge. The cesium leachability ranged from $10^{-6}$ to $10^{-1} \mathrm{~g} /\left(\mathrm{cm} \mathrm{m}^{2}\right)(d)$ depending on the formulation and the time of leaching. The data were strongly time dependent, approximately following $a t^{1 / 2}$ law." Given the size and weight of the leach specimens that were used $(2.38 \mathrm{~cm}$ diameter, $2.52 \mathrm{~mm}$ length, $20.9 \mathrm{mg}$ weight), the reported leach rates correspond to a range of values comprised between $2.7 \cdot 10^{.5}$ and $2.7 \mathrm{~g} /$ day and to release fractions of $1.3 \cdot 10^{-6}$ to $1.3 \cdot 10^{-1}$ per day.

Neilson's leachability data [Nellson, 1980; Colombo, 1982] examine the leach resistance of various solidification agents incorporating TRUwwaste in the form of incinerator ash. Some of the leaching periods extended for as long as 690 days. The reference radionuclides were plutonium isotopes. "The cumulative fractional (normalized to $\mathrm{V} / \mathrm{S}$ ) releases of plutonium over the approximately two year period ranged from about $2 \times 10^{-6}$ to $9 \times 10^{-5}$ for portland type I cement (depending on the leachant) and from about $2 \times 10^{-6}$ to $2 \times 10^{-5}$ for polyester-styrene. ... Data for bitumen ... gave slightly higher leach rates for bitumen compared to portland type I cement, but slightly lower than polyester-styrene." These data are more in line with the EPA assumed leach fractions. However, it must be realized that they refer to plutonium leaching only and to one particular wasteform.

In sum, the data cited by Rogers Associates does not generally support the leach fractions used in the PRESTO analyses. They indicate rather that the leach fractions used in PRESTO may be non-conservative. Of the authors that postulated a release mechanism, all assumed diffusion controlled release which is characterized by relatively high initial leach rates decreasing with time. Indeed, the ANS 16.1 standard leaching test for solidified waste forms interprets the results from short-term leaching tests in terms of a diffusion process. Furthermore, the data show a significant radionuclide-specific dependence. None of the authors explicitly recommended using a constant, nuclide-independent leach rate.

\subsubsection{Early releases}

EPA assumes that the disposal site is uniformly filled for 20 years and that no container breach occurs during this time. At the same time, the stored radionuclide inventory is allowed to decay. In the case of ${ }^{3} \mathrm{H}$, for instance, this means that only $61 \%$ of the initial inventory is modeled as being avallable for release to the general public.

The assumption of zero release during the time of institutional control of the site effectively increases the life of the containment barriers (trench cap and waste container) and, reportedly [BID, p. 11-16], has a significant impact on cutting down the maximum predicted dose to the CPG from short-lived radionuclides. In principle, however, releases from the trenches could start at any time after emplacement. 
Because of the above assumption, the EPA is very likely to underpredict the maximum dose to the CPG due to short-lived radionuclides, because the latter can be significantly decayed during the first few decades in the disposal facilit:

\subsection{Uncertainty analysis}

Uncertainty analyses performed by EPA [BID, Chapter 12] state that the total health hazards can be bounded to within a factor of two. Health hazards depend on cumulative dors Since the health hazards in the EPA studies depend primarily on the long-lived and mobile nuclides, e.g. C-14 and I-129, the above statement is true if inventories are known within a factor of two, as practically all these radionuclides will eventually be released from the disposal site.

Peak doses, however, are sensitive to the rates of infiltration, container degradation, leaching, and transport $\left(\mathrm{K}_{d}{ }^{\prime} s\right)$. It is improbable that these values are known with enough accuracy to insure that the peak dose is known within a factor of two. In fact, given the low degree of acceptability and completeness of the leach-and-transport models that were used, this claim becomes even less probable.

Furthermore, it must be realized that the EPA uncertainty analysis for the peak dose was not pertormed based on PRESTO-CPG but rather on an analytical solution based on a partition limited release from the waste. Only a humid site was modeled and the parameter values for $\mathbf{K}_{\mathrm{d}}$, degree of trench cap tailure, length of disposal site, distance from trench bottom to the aquifer, water velocity in the soil, and water velocity in the aquifer were sampled from probability distribution functions. The distribution functions were highly peaked around the mean with a standard deviation of at most $25 \%$. Aquifer thickness, porosity, and waste inventory were assumed to be known. The peak dose scales either linearly with inventory and inversely to thickness and porosity. Due to the narrow distribution functions used, the predicted uncertainty was very small.

Since the uncertainty analysis was not performed with PRESTO-CPG, its relevance with respect to the CPG analyses is unclear. Furthermore, the narrowness of the distributica functions and the fact that the modeling is simpler than in the PRESTO code, make the results of the analysis suspect. 


\section{CONCLUSIONS}

The overall conclusion of this review is that the generic analyses performed in support of the proposed version of 40 CFR 193 are subject to question; nor can the final results be claimed to either underestimate or overestimate doses. This is because the EPA predictions rely upon a high level of empiricism while, at the same time, are lacking the ancillary analyses that would validate data, models and release scenarios.

Several observations have been made indicating that:

1. Model assumptions were used which contradict the available experimental data, e.g., the leach model.

2. Models were used which do not follow the progressive evolution in time of the physical characteristic of the site. For instance, it appears that the total arnount of water infiltrating a trench every year is determined a priori, without supporting data, by the code user.

3. Not all pathways were explored, e.g., airborne releases of volatile compounds and elements were not evaluated.

4. The source term inventory underestimates the actual inventories of key radionuclides and it does not reflect the most typical compositions found at commercial and at DOE-controlled LLW sites.

5. The uncertainty analysis was performed on a different set of models from those implemented in the PRESTO codes. It also used highly-peaked parameter distribution functions without justification.

6. The relative position of the drinking well with respect to the closest disposal trenches is poorly modeled, potentially underestimating the dose to the CPG. Also, the radionuclide migration model within the aquifer is highly empirical with the code user supplying water velocity and plume aperture.

7. The analyses did not address potential intruder scenarios after the period of active institutional controi of the LLW sites is over. However, it appears to request them on a site-specific basis [BID, p. 8-12]. Thus, because an intruder could hypothetically disrupt a disposal facility and increase environmental releases, the EPA may have drafted a standard based on analyses that are less stringent than those that the EPA would expect of a license applicant.

The study does not supply an accurate means of estimating many parameters that strongly infiuence releases from the disposal facility. In particular, there is no justification of, or a methodology for calculating: 
a) Trench Cap Failure Rate. A linear failure rate is assumed up to a userspecified fraction of the trench cap.

b) Container Failure Rate. A user-supplied linear failure rate is assumed until $100 \%$ failure of all containers.

c) Solidified waste form leach fractions. Fractional release rate values used range from $10^{-3}$ to $5 \cdot 10^{-5}$ per year. Experimental data suggests that these values may greatly underpredict cumulative releases and release rates from solidified waste forms for many radionuclides for long periods of time.

d) Partition coefficients. The code has a data base containing values for the surface soil, trench, beneath the trench, and the aquifer. However, it is known that the values for partition coefficients may vary by several orders of magnitude depending on the local chemistry $(\mathrm{pH}$, Eh, competing ions, soil minerals, complexing agents, etc.).

Predictions based on generic, deterministic codes such as PRESTO are acceptable only if they can be argued to be conservative with respect to all disposal scenarios which can be potentially realized. Yet many observations have been presented that this may not be the case. A further observation to that effect (Section 2.2.6) is possibly that the usage of this code was overextended from a tool to compare alternative disposal methods and options to a tool to support decisions for establishing LLW standards. When generic codes, such as PRESTO, are applied to situations outside their intended range, they may seem to support more stringent criteria than are warranted by a more rigorous or a more conservative analysis. For example, a 1984 analysis [Pin, 1984] of the Oak Ridge site using their inventory (larger than in the EPA analyses) and more conservative assumptions: $K_{d}=0$ for all radionuclides; higher (measured) groundwater tlow rates; and smaller aquifer mixing zone, lead to dose rates estimates over two orders of magnitude larger than the limits proposed by EPA in 40 CFR 193.

In summary, the EPA study does not consider all of the possible release pathways that could be present; the models chosen were not always supported by relevant data, and the conservatism of some of the parameters specified are questionable. Thus, adoption of the EPA models may lead to estimates of release that are subject to major error and which may not be conservative. In this situation it may not be possible to use the recommended methodologies to demonstrate compliance with the EPA standard. 


\section{REFERENCES}

[ABEELE, 1981]

M.V. Abeele, M.L. Wheeler, and M.W. Burton, "Geohydrology of Bandelier Tuff," LA-8962MS, Los Alamos National Laboratory, Los Alamos, NM, October, 1981.

[AMANO, 1987]

H. Amano, C.T. Garten, Jr., and L.D. Lomax, "A Field Survey of Environmental Tritium in Areas Adjacent to ORNL Solid-Waste Storage Areas," ORNL/TM-10438, Oak Ridge National Laboratory, Oak Ridge, TN, May, 1987.

[ARORA, 1986]

H. Arora, and R. Dayal, "Leaching Studies of Cement-Based Low-Level Radioactive Waste Forms," NUREG/CR-4756, BNL-NUREG-52026, Brookhaven National Laboratory, 1986.

[BID, 1988]

U.S. Environmental Protection Agency, "Low-Level and NARM Radioactive Wastes, Draft Environmental Impact Statement for Proposed Rules, Volume 1, Background Information Document," EPA 520/1-87-012-1, June, 1988.

[CHRISTIANSEN, 1981]

H. Christiansen, "Solidification of Nuclear Waste in Concrete," Alternate Nuclear Waste Forms and Interactions in Geologic Media, U.S. Department of Energy, CONF-800517, p. 217 - 226, 1981.

[COLOMBO, 1979]

P. Colombo, and R.M. Neilson, "Properties of Radioactive Wastes and Waste Containers," Brookhaven National Laboratory, NUREG/CR-0619, 1979.

[COLOMBO, 1979a]

P. Colombo, and. R.M. Neilson, "Properties of Radioactive Wastes and Waste Containers, Progress Report No. 12, January - March, 1979," Brookhaven National Laboratory, NUREG/CR-1126, 1979.

[COLOMBO, 1980]

P. Colombo, and R.M. Neilson, "Properties of Radioactive Wastes and Waste Containers, Progress Report No. 14, July - September, 1979," Brookhaven National Laboratory, NUREG/CR-1251, 1980.

[COLOMBO, 1982]

P. Colombo et al., "Leaching Properties of Solidified TRU Contaminated Incinerator Ash," BNL-33671 (Informal Report), Brookhaven National Laboratory, September 1982. 
[CPG, 1987]

V. Rogers, C. Hung, "PRESTO-EPA-CPG: A Low-Level Radioactive Waste Environmental Transport and Risk Assessment Code, Methodology and Users Manual," EPA 520/1-87-026, RAE 8706/1-4, 1987.

[DOE, 1988]

DOE Order 5820.2A, "Radioactive Waste Management," September 26, 1988.

[EICHHOLZ, 1990]

G.G. Eichholz, M.F. Petelka, and J. Whang, "Leaching and Migration of Low-Level Wastes Under Unsaturated Conditions," Radioactive Waste Management and the Nuclear Fuel Cycle, Vol. 14(4), pp. 285 - 310, 1990.

[EPA, 1986]

J.M. Gruhlke, J. Neiheisel, and L. Battist, "Estimates of the Quantities, Form and Transport of Carbon-14 in Low-Level Radioactive Waste," EPA-520/1-86-019, Environmental Protection Agency, Washington, D.C., 1986.

[FR, 1982]

Federal Register, "Licensing requirements for land disposal of radioactive waste," Vol. 47, No. 248, Monday, December 27, 1982.

[FRANCIS, 1984]

A.J. Francis, "Anaciobic Microbial Transformations of Radioactive Wastes in Subsurface Environments," BNL-39648, Brookhaven National Laboratory, Upton, NY, April, 1984.

[FUHRMANN, 1989]

M. Fuhrmann and P. Colombo, "Leaching-Induced Concentration Profiles in the Solid Phase of Cement," in Environmental Aspects of Stabilization of Hazardous and Radioactive Wastes, ed. P. Cote and M. Gilliam, American Society for Testing and Materials publication $1033,1989$.

[GEE, 1988]

G.W. Gee, and D. Hillel, "Groundwater Recharge in Arid regions: Review and Critique of Estimation Methods," Hydrological Processes, Vol. 2, p. 255-266, 1988.

[GERHOLD, 1981]

W.F. Gerhold, E. Escalante, and B.T. Sanderson, "The Corrosion Behavior of Selected Stainless Steels in Soil Environments," NBSIR 81-2228, National Bureau of Standards, 1981.

[HUNG, 1983]

C.Y. Hung, "A Model to Simulate Infiltration of Rainwater Through the Cover of a Radioactive T'rench Under Saturated and Unsaturated Conditions," Role of the Unsaturated Zone in Radioactive and Hazardous Waste Disposal, ed. J.W. Mercer, et. al., Ann Arbor Science, 1983. 
[KIBBEY, 1979]

A.H. Kibbey, and H.W. Goodbee, "Physicochemical Characterization of Solidification Agents Used and Products Formed with Radioactive Wastes at Nuclear Power Plants," Scientific Basis for Nuclear Waste Management 1, (ed. G.J. McCarthy), p. 495-498, 1979.

[MORCOS, 1980]

N. Morcos, and A.J. Weiss, "Properties of Radioactive Wastes and Waste Containers, Quarterly Progress Report, April - June, 1980," Brookhaven National Laboratory, BNL28856, 1980.

[NEIHEISEL, 1983]

J. Neiheisel, "Prediction Parameters of Radionuclide Retention at Low-Level Radioactive Waste Sites," U.S. Environmental Protection Agency, EPA-520/1-83-025, 1983.

[NEILSON, 1979]

R.M. Neilson, and P. Colombo, "Solidification of Liquid Concentrate and Solid Waste Generated as By-Products of the Liquid Radwaste Treatment Systems in Light-Water Reactors," Management of Low-Level Radioactive Waste, (eds. M.W. Carter, A.A. Moghissi, and B. Kahn), p. 493 - 512, 1979.

[NEILSON, 1980]

R.M. Neilson, and P. Colombo, "Status Report on Solidified TRU Waste Form Plutonium Leach Tests," Brookhaven National Laboratory, BNL-28856, 1980.

[NRC, 1990]

G.W. Roles, "Characteristics of Low-Level Radioactive Waste Disposed During 1987 Through 1989," NUREG-1418, U.S. Nuclear Regulatory Commission, 1990.

[OBLATH, 1989]

S.B. Oblath, "Leaching From Solidified Waste Forms under Saturated and Unsaturated Conditions," Environ. Sci. Technol,, V. 23, pp. 1098-1102, 1989.

[PEI, 1985]

PEI Associates, Inc., and Rogers \& Associates Engineering Corp., "Radiation Exposures and Health Risks Associated with Alternative Methods of Land Disposal of Natural and Accelerator Produced Radioactive Materials (NARM)," prepared for U.S. Environmental Protection Agency, Office of Radiation Programs, October 1985.

[PIN, 1984]

F.G. Pin, J.P. Witherspoon, D.W. Lee, J.B. Cannon, and R.H. Ketelle, "Radionuclide Migration Pathways Analysis for the Oak Ridge Central Waste Disposal Facility on the West Chestnut Ridge Site," ORNL/TM-9231, Oak Ridge National Laboratory, 1984.

[POP, 1987]

D.E. Fields, C.A. Little, F. Parraga, V. Rogers, C. Hung, "PRESTO-EPA-POP: A LowLevel Radioactive Waste Environmental Transport and Risk Assessment Code - Volume 1, Methodology Manual," EPA 520/1-87-024-1, RAE 8706/1-1, 1987. 
[RAE, 1984]

V.C. Rogers, "Shallow Land Disposal Trench $K_{d}$ Values for Use in PRESTO," Technical Information Memorandum, TIM 47/2, Rogers \& Associates Engineering Corporation, April 1984.

[RAE, 1985]

V.C. Rogers and R.D. Baird, "Maximum Annual Doses to Critical Population Groups Resulting from Alternative Methods of Land Disposal of Low-Level Radioactive Waste," RAE-847/2-3, Rogers and Associates Engineering Corp., prepared for the U.S. Environmental Protection Agency, 1985.

[ROMANOFF, 1957]

M. Romanoff, Underground Corrosion, National Bureau of Standards Circular 579, 1957.

[STONE, 1977]

J.A. Stone, "Evaluation of Concrete as a Matrix for Solidification of Savannah River Plant Waste," Savannah River Laboratory, DP-1448, 1977.

[SULLIVAN, 1991]

T.M. Sullivan, and C.J. Suen, "Low-Level Waste Source Term Model Development and Testing", in press, Brookhaven National Laboratory, 1991.

[WHEELER, 1975]

M.L. Wheeler, and J.L. Warren, "Tritium Containment After Burial of Contaminated Solid Waste," LA-UR-75-1109, Los Alamos National Laboratory, Los Alamos, NM, November, 1975.

[WILHITE, 1987]

E.L. Wilhite, "Concept Development for Saltstone and Low-Level Waste Disposal," Waste Management '87, Ed. R.G. Post, V. 2, p. 63, 1987. 


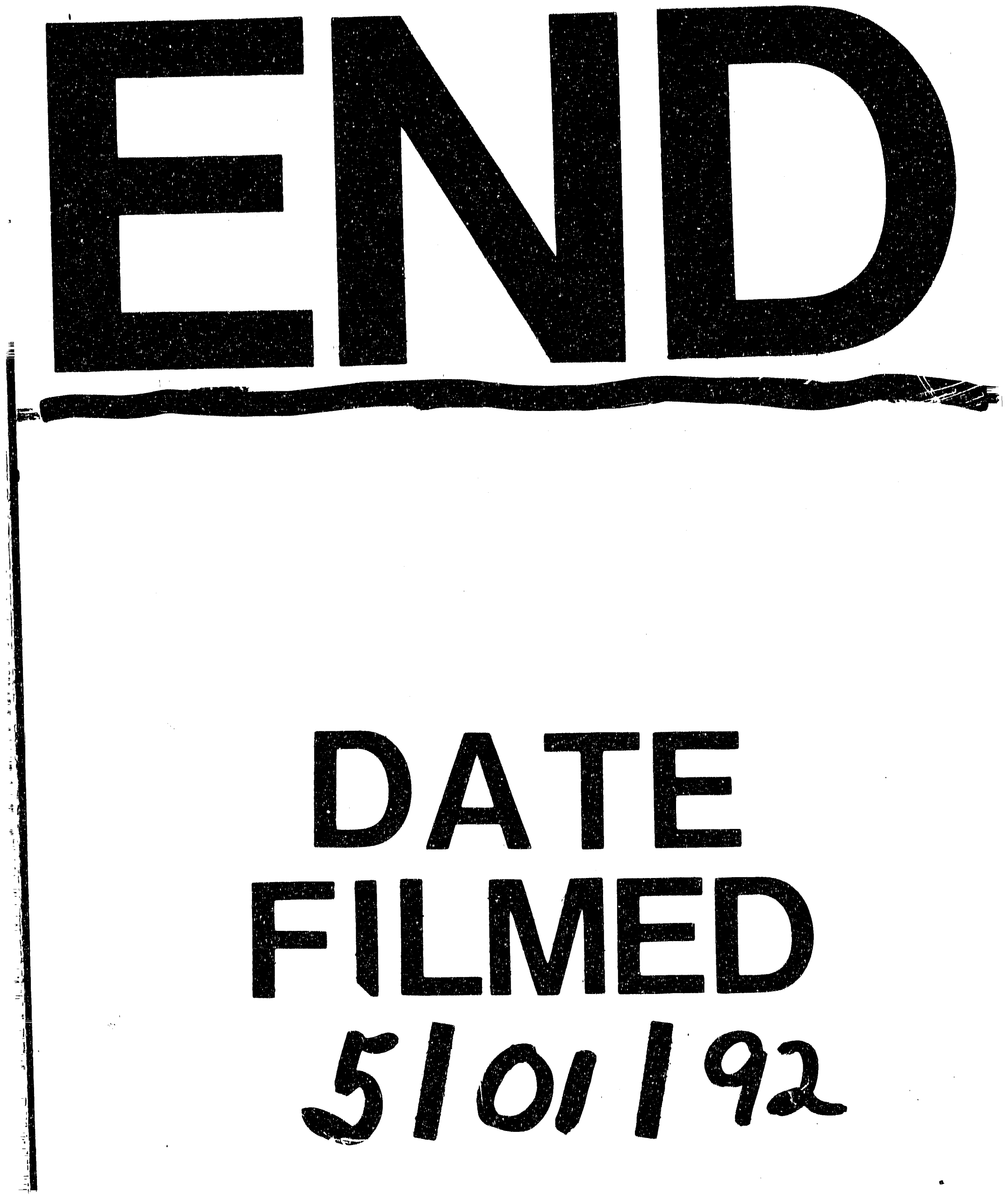


